\title{
Zooplankton Community Structure in a Cyclonic and Mode-Water Eddy in the Sargasso Sea
}

\author{
Bethany Rose Eden \\ College of William and Mary - Virginia Institute of Marine Science
}

Follow this and additional works at: https://scholarworks.wm.edu/etd

Part of the Marine Biology Commons, and the Oceanography Commons

\section{Recommended Citation}

Eden, Bethany Rose, "Zooplankton Community Structure in a Cyclonic and Mode-Water Eddy in the Sargasso Sea" (2008). Dissertations, Theses, and Masters Projects. Paper 1539617871.

https://dx.doi.org/doi:10.25773/v5-rq5r-vr45

This Thesis is brought to you for free and open access by the Theses, Dissertations, \& Master Projects at W\&M ScholarWorks. It has been accepted for inclusion in Dissertations, Theses, and Masters Projects by an authorized administrator of W\&M ScholarWorks. For more information, please contact scholarworks@wm.edu. 


\title{
Zooplankton Community Structure in a Cyclonic and Mode-water Eddy in the
} Sargasso Sea

\author{
A Thesis \\ Presented to \\ The Faculty of the School of Marine Science \\ The College of William and Mary in Virginia
}

In Partial Fulfillment

Of the Requirements for the Degree of

Master of Science

by

Bethany Rose Eden

2008 


\section{APPROVAL SHEET}

This Thesis is submitted in partial fulfillment of

the requirements for the degree of

Master of Science

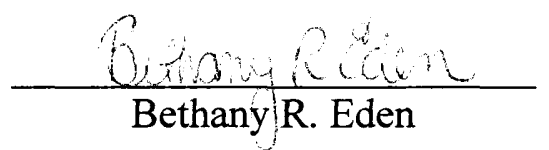

Approved by the Committee, April 2008
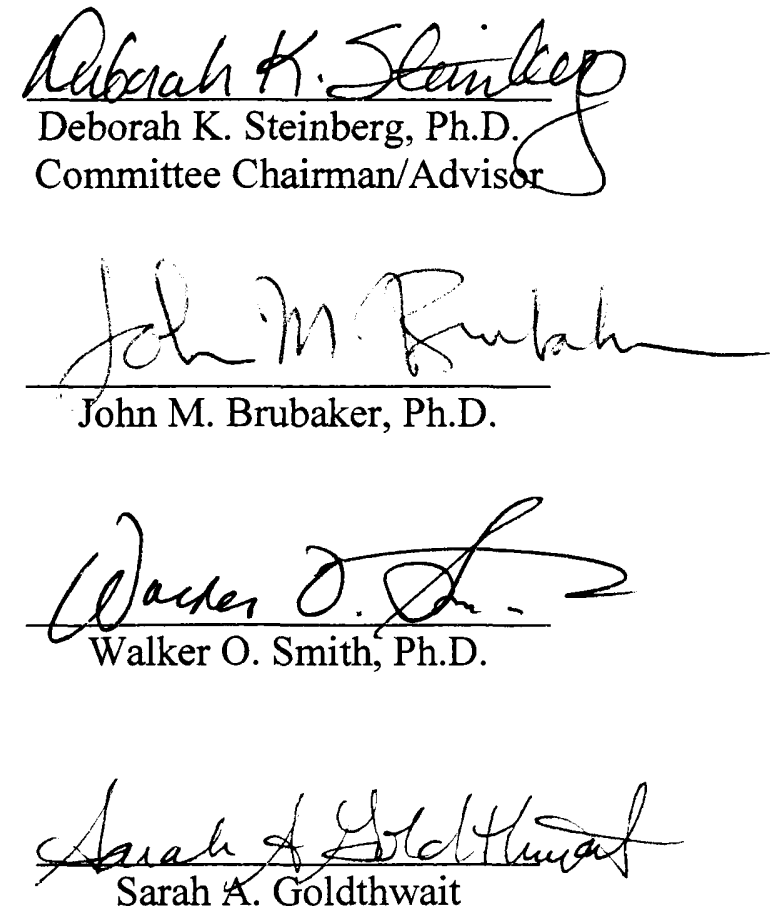

Humboldt State University

Arcata, California 


\section{DEDICATION}

I dedicate this thesis to my grandfather, Stanley Becker, who instilled in me at a young age, a curiosity and love for the environment. May his legacy live on through this and all my future endeavors. 


\section{TABLE OF CONTENTS}

\section{Page}

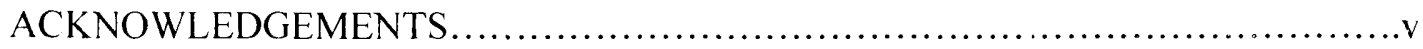

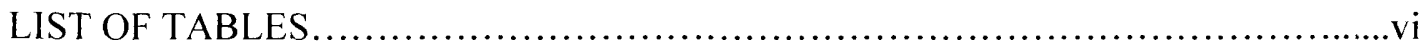

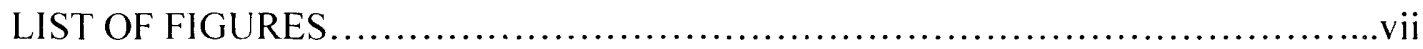

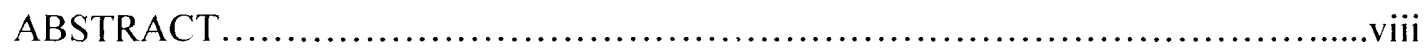

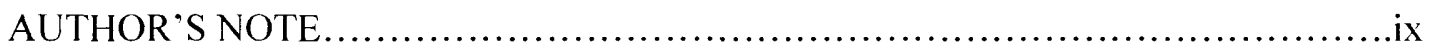

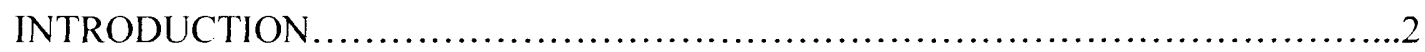

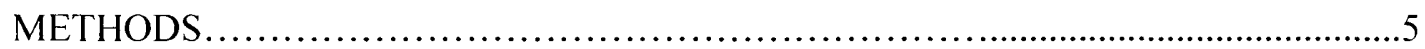

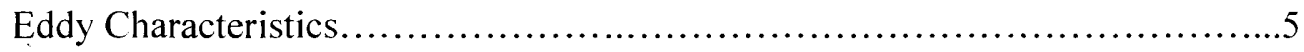

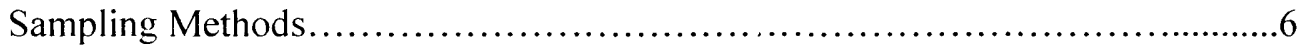

Statistical Analysis...............................................................

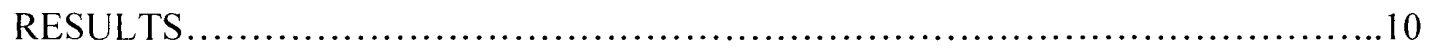

Community Composition .................................................... 10

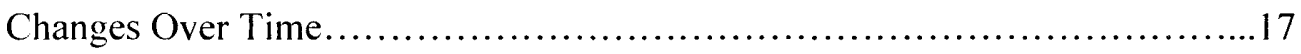

Comparison with Bermuda Atlantic Time-series Study (BATS) ................18

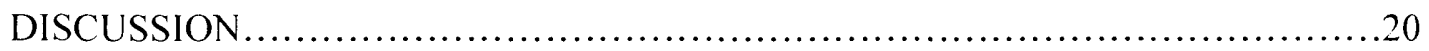

Zooplankton Community Dynamics............................................

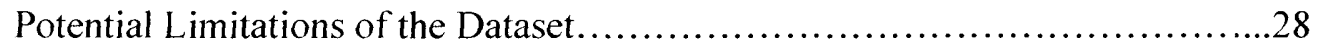

Eddies and Biogeochemical Cycling........................................

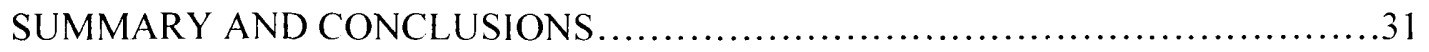

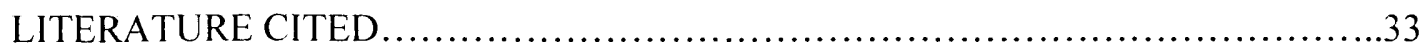

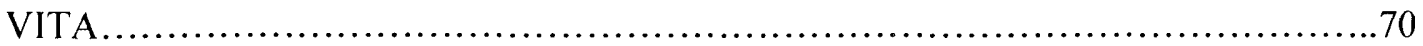




\section{ACKNOWLEDGEMENTS}

I am extremely grateful to Debbie Steinberg, for accepting me as an M.S. student, and opening my eyes to the unique world of zooplankton. Debbie's thoughtful guidance as an advisor, role model, and colleague has served to make me a more well-rounded and confident scientist. Thanks to my committee members John Brubaker, Walker Smith, and Sarah Goldthwait who gladly offered guidance in their individual areas of expertise. Not only did Sarah serve as my outside committee member, but she taught me everything I know about life on board a research vessel. I am extremely grateful for her patience and guidance while I learned to "rock the MOC."

I am so thankful for the efforts of Dennis McGillicuddy and the rest of the scientists onboard the R/V Oceanus and R/V Weatherbird II, all of whom worked extremely hard to see the EDDIES project through to completion. This project would not have been possible without the extremely competent captains and crews of these ships as well.

Thanks to the rest of the VIMS zooplankton ecology lab group; Grace Saba, Stephanie Wilson, and Rob Condon. While each had their own research projects to attend to, they were always willing to offer words of advice, help with samples, and fresh points of view. I thank Joe Cope for his assistance with statistics and graphs. Joe was always willing to use his vast knowledge of complex statistical and graphing software to make my data look polished.

Thanks to my roommate Meghan Robertson who has graciously shared a house with me for the past two years. I wouldn th have survived without trips for sushi and Mexican food, impromptu "car dances", and trips to Sonic for pellet ice at $11 \mathrm{pm}$. My best friend Nichole Diem was a constant "reality check". always reminding me of what was important and encouraging me to see this through to completion. I have no words to say how thankful I am to my boyfriend Jonathan. He has been a constant source of patience, support, inspiration. love, and most importantly, laughter. He always knows when I need a good laugh, and makes sure I take time out to have one. Thank you for learning words like "copepod" and "dinoflagellate", and making what"s important to me, important to you.

Most importantly, I'm extremely grateful to my family, who have supported me throughout the course of my education. Even though they were far in miles, they were always close in heart. My brother Jeremy and sister Lydia have been good reminders not to take life too seriously. To my parents, thank you for always being my biggest supporters. You have encouraged me to strive for my best, and to not settle until my goals are attained. 


\section{LIST OF TABLES}

Page

Table 1 Diel vertical migration indices for major taxa of zooplankton

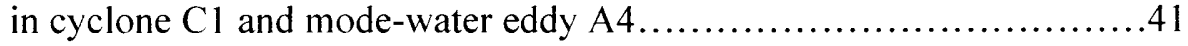

Table 2 Diel vertical migration indices for major taxa of zooplankton

at BATS ....................................................... 43 


\section{LIST OF FIGURES}

Figure $1 \quad$ Cyclone $\mathrm{C} 1$ satellite imagery and fluorescence .......................44

Figure 2 Mode-water eddy A4 satellite imagery and fluorescence...............46

Figure 3 Comparison of epipelagic integrated abundance of copepods between cyclone $\mathrm{Cl}$, mode-water eddy $\mathrm{A} 4$, and 2004/2005 BATS summer means.

Figure 4 Comparison of epipelagic integrated abundance of other crustaceans between cyclone $\mathrm{C} 1$, mode-water eddy $\mathrm{A} 4$, and 2004/2005 BATS summer means.

Figure 5 Comparison of epipelagic integrated abundance of gelatinous zooplankton between cyclone $\mathrm{C} 1$, mode-water eddy $\mathrm{A} 4$, and 2004/2005 BATS summer means.

Figure 6 Comparison of epipelagic non-copepod percent abundance between cyclone $\mathrm{C} 1$ and mode-water eddy $\mathrm{A} 4$....

Figure 7 Day/night depth profiles of copepod abundance at the center and outside of mode-water eddy A4 ...............................56

Figure $8 \quad$ Water column percent abundance of non-copepod zooplankton during day and night in mode-water eddy $\mathrm{A} 4 \ldots \ldots \ldots \ldots \ldots . .58$

Figure 9 Day/night depth profiles of other crustacean abundance at the center and outside of mode-water eddy A4....

Figure 10 Day/night depth profiles of gelatinous zooplankton abundance at the center and outside of mode-water eddy A4

Figure 11 Day/night depth profiles of gelatinous zooplankton abundance at the center and outside of mode-water eddy A4.

Figure 12 Changes in abundance of total copepods, chaetognaths, and ostracods over time in cyclone $\mathrm{C} 1$

Figure 13 Changes in abundance of total copepods, chaetognaths, and ostracods over time in mode-water eddy A4. 


\begin{abstract}
Recent evidence suggests that mesoscale eddies are an important mechanism for supplying nutrients to the surface waters of oligotrophic gyres. However, little is known about the biological response to these physical perturbations. Because mesozooplankton play a key role in food-web interactions and the flux of carbon and other elements from surface waters, changes in mesozooplankton community structure can affect biogeochemical cycling. During the summers of 2004 and 2005, respectively, we followed the development of a cyclonic eddy and an anti-cyclonic mode-water eddy in the Sargasso Sea. Zooplankton tows were conducted across both eddies using a Multiple Opening and Closing Net Environmental Sensing System (MOCNESS), which sampled 9 discrete depth intervals between 0-700 $\mathrm{m}$.

Comparison of the abundance of major taxa of mesozooplankton in the upper $150 \mathrm{~m}$ at eddy center and outside the eddies (day and night), indicated that the cyclone and modewater eddy supported similar mesozooplankton communities, with little difference inside vs. outside the eddies. However, a comparison with the Bermuda Atlantic Time-series Study (BATS) site, used as an alternative outside station, indicated significantly higher abundance of several zooplankton taxa inside both eddies. In both eddies copepod peak abundance occurred in the 50-100 $\mathrm{m}$ depth interval, coincident with the chlorophyll $a$ maximum. suggesting elevated food concentration in the eddies may be influencing zooplankton vertical distribution. The two eddies differed in the strength of diel vertical migration of zooplankton, as indicated by the ratio of night:day abundance in the epipelagic zone which was higher at the center of the mode-water eddy for most taxa. Over the sampling interval of 1-2 months, abundance of the three most common taxa (copepods, chaetognaths, and ostracods) decreased in the cyclone, and increased in the mode-water eddy. This further supports previous findings that the cyclone was in a decay phase over the sampling period, while the mode-water eddy was sustaining high nutrient and phytoplankton concentrations for the duration of sampling. A more detailed analysis of community structure in the mode-water eddy $(0-700 \mathrm{~m})$ indicated no significant difference between eddy center vs. outside the eddy in the abundance of any taxa at any specific depth interval. However, the $0-700 \mathrm{~m}$ integrated abundance of doliolids was significantly higher inside the eddy. The presence of a mesopelagic (200$700 \mathrm{~m}$ ) layer of lepadid barnacle cyprids highlights the potential of these eddies for transport and dispersal of biota. We conclude that eddies can influence zooplankton behavior and alter zooplankton community structure in ways which affect biogeochemical cycling in the open ocean.
\end{abstract}




\section{AUTHOR'S NOTE}

The primary research of this thesis was written in the format of the journal to which it is to be submitted. Therefore, this thesis was written to represent myself and my coauthors. The citation is as follows:

Eden, B. R., Steinberg, D. K., Goldthwait, S. A., In Prep. Zooplankton Community Structure in a Cyclonic and Mode-water Eddy in the Sargasso Sea. Deep Sea Research I or Journal of Plankton Research. 
Zooplankton Community Structure in a Cyclonic and Mode-water Eddy in the Sargasso Sea 


\section{Introduction}

The influence of physics on biology has been widely studied on both large and small scales. Within this scope of physical influence is what is known as the "internal weather of the sea". or the oceanic mesoscale (McGillicuddy 2001). Mesoscale physical features can change both the chemical and biological environment which can result in alteration of biogeochemical cycling (McNeil et al. 1999). It is important to understand these complex interactions, as mesoscale processes may be linked to the supply of new nutrients and elevated productivity in oligotrophic systems (Jenkins and Goldman 1985). Eddy-induced upwelling due to the shoaling of isopyncnal surfaces allows for the injection of nutrients into the euphotic zone, releasing phytoplankton from nutrient limitation common in oligotrophic systems, and stimulating new primary production (McGillicuddy and Robinson 1997, Oschlies and Garçon 1998, McGillicuddy et al. 2007). Evidence suggests that mesoscale eddies may supply the missing nutrients necessary to close the new nutrient budget in the oligotrophic waters of many subtropical gyres (McGillicuddy et al. 1998). Recent studies of mesoscale eddies in the Sargasso Sea (McGillicuddy et al. 2007) and in the lee of the Hawaiian Islands (Benitez-Nelson et al. 2007) have shed new light on the complex physical (Dickey et al. in press), chemical (Ledwell et al. in press), and biological (Goldthwait and Steinberg in press) processes within these features.

Mesoscale features are important in controlling the structure and productivity of marine planktonic communities (Owen 1981, Angel and Fasham 1983, Mann and Lazier 1991, Olson 1991, Bibby et al. in press, Ewart et al. in press, Landry et al. in press a, McAndrew et al. in press). However, with the exception of the Bermuda Atlantic Time- 
series Study (BATS), which has recorded the biogeochemical and sea-level anomaly signals of several mesoscale features that have passed through this study site over the last 18 years (Michaels 1995, Sweeney et al. 2003, Mouriño-Carballido and McGillicuddy 2006. Mouriño-Carballido in prep.), few studies have attempted a detailed quantification of the mesozooplankton community response to the passage of mesoscale eddies in oligotrophic systems such as the Sargasso Sea. Characterizations of mesozooplankton community structure (primarily in terms of zooplankton biomass) in mesoscale features have been conducted on Gulf Stream rings (The Ring Group 1981. Wiebe 1982, Davis and Wiebe 1985, Hitcheock et al. 1985, Wormuth 1985) the California Current system (Haury 1984, Bucklin 1991, Huntley et al. 2000), the Haida eddies of the Gulf of Alaska (Mackas and Galbraith 2002, Batten and Crawford 2005, Makas et al. 2005. Tsurumi et al. 2005), the Eastern Australian Current (Scott 1981, Tranter et al. 1983), the Arabian and Black Seas (Piontkovski et al. 1995, Arashkevich et al. 2002), the island-induced eddies of the North Atlantic (Hernández-León et al. 2001, Yebra et al. 2005), the Agulhas/Benguela system off southern Africa (Lutjeharms and Valentine 1988. Pakhomov and Perissinotto 1997), and a recent study in the southeastern lee of the Hawaiian islands (Landry et al. in press b). Several of these studies highlight eddyinduced changes in the zooplankton community (Davis and Wiebe 1985, Tsurumi et al 2005, Hernández-León et al. 2001, Landry et al. in press b, Goldthwait and Steinberg in press).

In this study, we investigate the effects of two types of mesoscale eddies, cyclones and mode-water eddies, on mesozooplankton community taxonomic structure in 
the Sargasso Sea. Mesoscale eddies are ubiquitous in the Sargasso Sea, are roughly 150$200 \mathrm{~km}$ in diameter, and can persist from several months to a year (McGillicuddy et al. 2007). The physical characteristics of both cyclonic and mode-water eddies are known to stimulate a biological response (Benitez-Nelson et al. 2007. McGillicuddy et al. 2007, Li and Hansell in press). Both eddy types exhibit a characteristic shoaling of isopyncnal surfaces which allows for the stimulation of both phytoplankton (Bibby et al. in press. Landry et al. in press a) and zooplankton (Goldthwait and Steinberg in press, Landry et al. in press b) through upwelling of deep, nutrient rich waters within the area occupied by the eddy. Mesoscale features can influence zooplankton horizontal distribution (Wiebe et al. 1976 b), vertical distribution-both on a long-term (eddy lifetime) and on a diel cycle (Piontkovski et al. 1995), physiology (Boyd et al. 1978), and species succession (Wiebe et al. 1976 b). Most recently, Goldthwait and Steinberg (in press) showed elevated mesozooplankton biomass, enhanced fecal pellet flux, and increased carbon export by diel vertical migration in cyclonic and mode-water eddies in the Sargasso Sea, but did not address changes in individual taxa as a result of eddy pertubation. Similarly, in the subtropical Pacific, Landry et al. (in press b) show elevated mesozooplankton biomass. epipelagic abundance, and carbon export by migratory mesozooplankton inside cyclone Opal as compared to outside the cyclone.

By understanding how mesozooplankton community structure is affected by the influence of mesoscale eddies, we can further characterize the role that mesoscale eddies play in the alteration of biogeochemical cycles. While much attention has been paid to the role of phytoplankton assemblages as a factor controlling transfer efficiency of carbon to depth, the role of consumers is not as well understood. Changes in zooplankton taxa or 
abundance can also control the flux of carbon and other elements to depth due to resultant changes in grazing, fecal pellet size and sinking rates, and vertical migration behavior (e.g., Michaels and Silver 1988, Steinberg et al. 2000). Understanding how mesoscale eddies affect zooplankton community structure will enhance our understanding of carbon cycling and sequestration, particularly in oligotrophic gyres where total biological production is thought to be relatively low.

\section{Methods}

\subsection{Eddy Characteristics}

Two target eddy features were surveyed aboard the $R / V$ Oceanus: a cyclonic eddy (C.1) from 11 June - 3 July and 25 July - 12 August in 2004 (Fig. 1), and an anti-cyclonic mode-water eddy (A4) from 20 June - 15 July and 7 - 25 August in 2005 (Fig. 2). Although the target features exhibited opposite rotational directions (counter-clockwise for $\mathrm{C} 1$ and clockwise for A4) as well as opposite directions of displacement of the permanent thermocline (upwards for $\mathrm{C} 1$ and downwards for A4), both eddies were characterized by the shoaling of upper ocean isopycnals resulting in nutrient injection into the euphotic zone ( $\mathrm{Li}$ and Hansell in press). Temperature and salinity sampling within the eddies characterized eddy $\mathrm{C} 1$ as an oblong feature with lateral extensions to the northeast and southwest. Eddy A4 was characterized as a relatively round feature with a lens of $18^{\circ} \mathrm{C}$ mode-water at its center (McGillicuddy et al. 2007).

The deep chlorophyll $a(\mathrm{Chl} a$ ) maximum occurred between $50-100 \mathrm{~m}$ in both eddies; however both the location of highest $\mathrm{Chl} a$ concentration and the phytoplankton species composition differed between $\mathrm{C} 1$ and $\mathrm{A} 4$. Elevated fluorescence values occurred 
primarily along the periphery of eddy $\mathrm{Cl}$ (Fig. 1), while the diatom bloom in eddy A4 was localized to within ca. 20-30 km of eddy center (Fig. 2) (McGillicuddy et al. 2007, Bibby et al. in press). Analysis of the phytoplankton assemblage indicated Prochlorococcus spp.. Synechococcus spp., pelagophytes, and prymnesiophytes constituted the largest percentage of Chl $a$ in the deep chlorophyll maximum of eddy $\mathrm{Cl}$, while analysis of the phytoplankton assemblage in eddy A4 indicated extremely high Chl $a$ values associated with a bloom of the chain-forming diatom Chaetoceros spp.

(McGillicuddy et al. 2007, Bibby et al. in press). This large diatom bloom was unique to eddy A4, as high numbers of diatoms were not observed in eddy $\mathrm{C} 1$.

\subsection{Zooplankton Sampling}

Zooplankton were collected during the day and night at the center and outside of both eddies, and additionally at the periphery of C1. Daytime tows were conducted between $1000 \mathrm{~h}$ and $1400 \mathrm{~h}$ and nighttime tows between $2200 \mathrm{~h}$ and $0200 \mathrm{~h}$ (local time). Due to the enhanced fluorescence on the periphery of cyclonic eddy $\mathrm{C} 1$, tow locations were designated as either "center", "periphery", or "outside". Tows conducted in anticyclonic mode-water eddy A4 were designated as either "center" or "outside" due to the localized nature of the diatom bloom at eddy center. "Outside" eddy tow locations were not designated strictly on a standard distance from eddy center, but rather on examination of shipboard physical and chemical data which indicated the presence or absence of eddy influence (Acoustic Doppler Current Profiler, XBT, CTD profiles). Therefore, stations designated as "outside" of eddy $\mathrm{Cl}$ are analogous with "outside" eddy A4 stations in that 
they are representative of similar physical environments (little to no eddy influence); however they are not representative of points equidistant from eddy center.

Zooplankton were collected as described in Goldthwait and Steinberg (in press) using a Multiple Opening and Closing Net Environmental Sensing System (MOCNESS) with 9 sampling nets of $150 \mu \mathrm{m}$ mesh mounted on a $1 \times 1 \mathrm{~m}$ frame (Wiebe et al. $1976 \mathrm{a}$ ). The MOCNESS was outfitted with a pressure sensor, flow meter, inclinometer, Sea-Bird temperature and conductivity probes, and GPS. The MOCdata software was used for real-time monitoring of environmental and flight data, and for data processing. The following discrete depth intervals were sampled on the upcast: $0-50,50-100,100-150$, 150-200, 200-300, 300-400, 400-500, 500-600, and 600-700 m. Each net deployment lasted $\sim 2-2.5 \mathrm{~h}$ with nets sampling for the final $\sim 1.3 \mathrm{~h}$. Contents of each net were collected in filtering cod-ends fitted with $150 \mu \mathrm{m}$ mesh. Fifteen MOCNESS tows were conducted in eddy C1 (2004), and 21 in eddy A4 (2005). Due to the higher sample size, we conducted a more detailed analysis of zooplankton community structure with depth in mode-water eddy A4.

Upon recovery nets were rinsed with seawater and the cod ends were removed. The contents of each cod end were then split using a Folsom plankton splitter with half preserved in $4 \%$ borax-buffered formaldehyde for analysis of community structure. and the other half size fractionated for biomass using methods similar to Landry et al. (2001) and Madin et al. (2001) (for biomass restilts, see Goldthwait and Steinberg in press).

The BATS summer zooplankton samples used as a comparison (as alternative "outside" eddy samples) in this study were collected on BATS cruises during the months of June, July, and August, 2004 and 2005. The samples were collected by BATS 
scientists according to the methods described by Madin et al. (2001), using a $1 \mathrm{~m}^{2}, 202$ $\mu \mathrm{m}$ mesh net towed obliquely through the mixed layer to an approximate depth of $200 \mathrm{~m}$. This slightly larger mesh size could lead to underestimation of 150- $200 \mu \mathrm{m}$ zooplankton, such as small copepods, or more effective sampling of larger taxa, in the BATS summer samples as compared with the MOCNESS (150 $\mu \mathrm{m}$ mesh). However, neither bias was apparent in the data set as indicated by no significant differences in the epipelagic abundance of some key large grazers (e.g., euphausiids, ANOVA p $>0.05$ ) between BATS and the eddies (also see results). Preserved ( $5 \%$ buffered formaldehyde) quarter-split samples of BATS summer tows were then analyzed by the methods of this study. BATS day and night samples were then averaged to determine summer mean (June-August) zooplankton abundance for each sampling year (2004, 2005). Six BATS zooplankton samples were enumerated each year $(2004,2005)$ for daytime tows, six for nighttime tows during 2005, and five for nighttime tows during 2004.

\subsection{Taxonomic Community Structure Analysis}

Preserved samples were analyzed using an Olympus SZX12 stereo dissecting microscope under dark and light field illumination. Zooplankton were identified to major taxa (e.g., calanoid copepods, non-calanoid copepods, chaetognaths), with some conspicuous taxa identified to genus or species (e.g., Pleuromamma spp. copepods, Lepas pectinata barnacle cyprids). Copepods were broken into two groups, calanoid and noncalanoid, the latter comprising poecilostomatoid, cyclopoid, and harpacticoid copepods. Each sample was gently rinsed through two nested sieves (2000 and $150 \mu \mathrm{m})$. All animals collected on the $2000 \mu \mathrm{m}$ sieve were identified and enumerated. Animals 
remaining on the $150 \mu \mathrm{m}$ sieve were subsampled with a Stempel pipette $(5 \mathrm{ml})$ before identification and enumeration. A minimum of 100 animals were identified in the 150 $2000 \mu \mathrm{m}$ fraction, resulting in examination of $1 / 320-1 / 2$ of the total abundance of zooplankton collected per sample.

\subsection{Vertical Structure}

In order to quantify the presence and extent of vertical migration of the various taxa at each sampling location, we calculated both night:day $(\mathrm{N}: \mathrm{D})$ abundance ratios in the upper $150 \mathrm{~m} \mathrm{(eddy} \mathrm{Cl}$ and $\mathrm{A} 4$ ) as an indicator of the "strength" of migration and the night vs. day change in weighted mean depth of zooplankton abundance (eddy A4) as an indicator of migration amplitude. $\mathrm{N}: \mathrm{D}$ ratio was calculated by integrating the abundance of a given taxa over the upper $150 \mathrm{~m}$ (number of individuals $\mathrm{m}^{-2}$ ) and dividing the average night value by the average day value. Weighted mean depth $(\mathrm{m})$ was calculated as:

$$
\mathrm{WMD}=\Sigma\left(n_{i} * z_{i} * d_{i}\right) / \Sigma\left(n_{i} * z_{i}\right)
$$

where $d_{i}$ is the depth of a sample $i$ (center of the depth interval, $\mathrm{m}$ ), $z_{i}$ is the thickness of the depth interval (m), and $n_{i}$ is the density of individuals in the depth interval (number of individuals $\mathrm{m}^{-3}$ ) (Anderson et al. 1997, 2001, 2004; Steinberg et al. in press a). The amplitude of migration ( $\triangle W M D$ ) was calculated as day WMD minus night WMD (m). 


\subsection{Statistical Analysis}

Comparisons between locations (center vs. periphery vs. outside for eddy $\mathrm{C}$. or center vs. outside for eddy A4) within an eddy were done using 3-factor repeated measures ANOVAs (data were sorted by depth, location, and time of day: see Results for details). Where data did not fit the normality and homogeneity of variance assumptions of the ANOVA, data were transformed using square root, log. reflect, arcsine, or inverse transformations. We assumed an a priori level of significance of alpha $=0.05$ for all comparisons.

\section{Results}

\subsection{Eddy-eddy comparison in the epipelagic zone}

Zooplankton abundance was integrated over the upper $150 \mathrm{~m}$ of the water column to compare the epipelagic abundance of major taxa between the two types of eddies (cyclone $\mathrm{Cl}$ versus mode-water eddy A4). There were no significant differences between the two eddy types in abundance of any taxonomic group when comparing eddy center and outside the eddies during the day or night ( $>>0.05,3$-way ANOVA) (Fig. 3, 4, 5). There is no eddy vs. eddy comparison at periphery stations because the eddy periphery was only sampled in eddy $\mathrm{C} 1$ in 2004. A large amount of variation in zooplankton abundance was observed in both eddies and at all locations sampled.

The contribution of each taxonomic group to the total zooplankton community was also determined for the epipelagic zone (upper $150 \mathrm{~m}$ ) in each eddy and compared. In both eddies copepods comprised $\sim 75-95 \%$ of the total community, inside, on the periphery, and outside the respective eddies. In order to compare the taxonomic 
composition between eddy types (C1 versus A4) in more detail, we examined the noncopepod zooplankton, which were largely comprised of four other taxonomic groups (chaetognaths, ostracods, pteropods, and siphonophores) (Fig. 6). The non-copepod zooplankton taxa were also similar between the two eddy types (C 1 vs. A4), with the exception of the chaetognaths and doliolids which, although not significant $(p>0.05)$, appear to comprise a greater percentage of the epipelagic zooplankton community at the center of mode-water eddy A4. and siphonophores which appear to comprise a greater percentage of the epipelagic zooplankton community outside eddy A4 (Fig. 6).

Comparison of the strength of vertical migration ( $\mathrm{N}: \mathrm{D}$ ratio) between the two eddy types suggests a more active migration across major taxa in the mode-water eddy as compared to the cyclone, as 11 out of 16 of the identified taxonomic groups in the center of the mode-water eddy had higher N:D ratios than in the center of the cyclone, including the most abundant taxa, the copepods (Table 1).

\subsection{Anti-cyclonic mode-water eddy A4}

\subsubsection{Copepods}

As expected, copepods were the most abundant taxa of zooplankton present day and night, both inside and outside of eddy $\mathrm{A} 4$, comprising $\sim 75-95 \%$ of the total zooplankton community abundance, depending on depth. The peak abundance of copepods occurred in the 50-100 m depth interval, with calanoid copepods reaching a mean density ( \pm 1 s.d.) of $533 \pm 223$ individuals $\mathrm{m}^{-3}$ during nighttime tows at eddy center, and non-calanoid copepods reaching a mean density of $284 \pm 187$ individuals $\mathrm{m}^{-3}$ during daytime tows at eddy center (Fig. 7). There was no significant difference in abundance 
of copepods inside vs. outside of eddy A4 at any depth ( $p>0.05$, ANOVA), although at their peak depth, both calanoid and non-calanoid copepod abundances appear higher at eddy center (Fig. 7). At deeper depth intervals both calanoid and non-calanoid copepod abundances are mostly higher outside the eddy (Fig. 7). As a broad taxonomic group, copepods did not exhibit a strong diel vertical migration with $\mathrm{N}$ :D abundance ratios in the upper $150 \mathrm{~m}$ of 1.2 (calanoids) and 1.1 (non calanoids) at eddy center and 0.9 (both groups) outside the eddy (Table 1). This relatively low N:D ratio was further supported by small day-night changes in WMD of $33 \mathrm{~m}$ (calanoids) and $38 \mathrm{~m}$ (non calanoids) at eddy center, and $23 \mathrm{~m}$ and $17 \mathrm{~m}$, outside the eddy (Table 1). Certainly some individual copepod taxa such as Pleuromamma spp. (Calanoida) were strong migrators. The abundance of Pleuromamma spp. copepods in the epipelagic zone increased from near zero in the day to 0.3 individuals $\mathrm{m}^{-3}$ at night both inside and outside the eddy. This increase in nighttime abundance was supported by $\mathrm{N}: \mathrm{D}$ ratios at eddy center of 76 , and outside the eddy of 64 , as well as a high $\triangle$ WMD (496 $\mathrm{m}$ at center and $487 \mathrm{~m}$ outside) (Table 1). There was however, no significant difference in abundance of Pleuromamma spp. inside vs. outside the eddy ( $p>0.05$ ANOVA).

\subsubsection{Other Crustacea}

After the copepods, ostracods were the next most abundant group of crustaceans, comprising between $5 \%$ and $75 \%$ of the non-copepod zooplankton community at eddy center, depending on depth, and a similar percentage outside the eddy (Fig. 8). Peak ostracod density averaged $31 \pm 4.5$ individuals $\mathrm{m}^{-3}$ during nighttime tows outside the eddy (Fig. 9). Ostracod abundance appears to be higher outside the eddy at nearly all depths. 
but the results were not significant $(p>0.05$ ANOVA). Ostracods exhibited pronounced diel vertical migration that was stronger at eddy center, with $\mathrm{N}: \mathrm{D}$ ratios of 1.7 (center) and 1.4 (outside), but was similar in amplitude inside and outside the eddy with a $\Delta$ WMD of $54 \mathrm{~m}$ and $55 \mathrm{~m}$, respectively (Table 1 ).

Decapods were the next most abundant group of crustaceans, reaching peak abundances of 2.5 individuals $\mathrm{m}^{-3}$ in the surface waters (Fig. 9) and comprising up to $4 \%$ of the non-copepod zooplankton community (eddy center, night) (Fig. 8). This group was primarily dominated by Lucifer sp. and a variety of decapod larvae and sergestids. As a group, decapods exhibited strong diel vertical migration at eddy center with a N:D ratio of 2.2 and a change in WMD of $100 \mathrm{~m}$ (Table 1). Outside the eddy decapod N:D ratio (1.3) and $\triangle \mathrm{WMD}(32 \mathrm{~m})$ was considerably lower, suggesting enhanced vertical migration behavior inside the eddy (Table 1).

Euphausiids and hyperiid amphipods were the least abundant of the crustaceans, although euphausiids comprised as much as $14 \%$, and hyperiid amphipods up to $\sim 6 \%$, of the non-copepod zooplankton community depending on depth and location (Fig. 8). Both of these groups tended to have peak abundances in nighttime tows outside the eddy, although abundances were not significantly different inside vs. outside the eddy $(p>0.05$ ANOVA) (Fig. 9). Euphausiids and hyperiid amphipods both exhibited marked diel vertical migration, with euphausiids having a higher $\mathrm{N}: \mathrm{D}$ ratio and $\triangle \mathrm{WMD}$ at eddy center ( 3.3 and $120 \mathrm{~m}$, respectively) vs. outside the eddy $(1.5$ and $81 \mathrm{~m})$ and hyperiid amphipods migrating more strongly outside the eddy (Table 1). Migrating hyperiid amphipods included members of the family Scinidae and Phronema spp. Other than Pleuromamma spp., gammarid amphipods exhibited the strongest diel vertical migration of all the 
taxonomic groupings ( $\mathrm{N}: \mathrm{D}$ ratio 19.5) at eddy center (and were absent from surface waters outside the eddy), and also had the highest $\triangle \mathrm{WMD}$ at eddy center (366 m) of all taxa, which was also higher than outside the eddy $(73 \mathrm{~m})$ (Table 1).

Cyprid stage larvae of the lepadid barnacle Lepas pectinata were found in night and daytime tows between 200 and $700 \mathrm{~m}$ at all stations in abundances that exceeded many of the other crustacean groups (Fig. 9). Peak abundance was between 500-600 m, and cyprids were absent from tows shallower than $200 \mathrm{~m}$ (Fig. 9). Barnacle cyprids made up as much as $\sim 32 \%$ of the zooplankton abundance between 200 and $700 \mathrm{~m}$ (Fig. 8). Although samples from $>150 \mathrm{~m}$ were not fully enumerated for cyclonic eddy $\mathrm{C} 1, \mathrm{a}$ cursory microscopic survey of samples from the 500-600 $\mathrm{m}$ depth interval indicated the presence of Lepas pectinata cyprids at all sampling locations in similar abundances to those found in mode-water eddy A4. The cyprids occupied a mean depth of ca. $520 \mathrm{~m}$ during day and night both inside and outside eddy A4 and did not vertically migrate (Table 1).

\subsubsection{Gelatinous Zooplankton}

Chaetognaths were the third most abundant taxa in the surface waters $(\sim 4-10 \%$ of the total community, depending on depth and sampling location) and were the most abundant gelatinous zooplankton taxa sampled (5-60\% of the non-zooplankton community) (Fig. 8). The vertical distribution of chaetognaths closely follows that of the copepods, with peak abundance in the 50-100 m depth interval (Fig. 10). Below $150 \mathrm{~m}$, chaetognath abundance decreased by an order of magnitude. Chaetognaths as a broad taxonomic group did not exhibit pronounced diel migration, as evidenced by a N:D ratio 
of 0.9 inside and outside the eddy, as well as negative day-night changes in WMD (Table $1)$.

Cnidarians such as siphonophores, were also common in the tows, comprising as much as $22 \%$ of the non-copepod zooplankton community during daytime tows outside the eddy (Fig. 8). Most siphonophores sampled were calycophoran (families Abylidae and Diphyidae). Siphonophores peaked in abundance in the surface waters, with abundance reduced by $\sim 75 \%$ below $150 \mathrm{~m}$ (Fig. 10). Similar to chaetognaths, siphonophores did not exhibit diel migration, with low N:D ratios at eddy center and outside the eddy (0.6), as well as negative day-night changes in WMD (Table 1). There was no significant difference in siphonophore or chaetognath abundance inside vs. outside the eddy $(p>0.05)$.

Doliolids were the only pelagic tunicate present in tows with abundance $>1$ individual $\mathrm{m}^{-3}$ (larvaceans were virtually absent from tows and were probably damaged beyond recognition). Doliolid abundance peaked between $50-100 \mathrm{~m}$ at $\sim 4$ ind. $\mathrm{m}^{-3}$ for nighttime tows at eddy center (Fig. 10). In the surface waters, doliolids appear more abundant at eddy center vs. outside, but this difference was not significant $(p>0.05$ ANOVA) (Fig. 10). Doliolids made up a larger percentage of the non-copepod zooplankton community in nighttime tows at eddy center vs. outside the eddy (Fig. 8), most likely because doliolids migrated more strongly at eddy center ( $N$ :D of 1.6) vs. outside (N:D of 1.2) (Table 1). Doliolids were the only taxonomic group that showed significantly higher integrated water column abundance $(0-700 \mathrm{~m})$ at eddy center vs. outside the eddy for both day $(p=0.006$, ANOVA) and nighttime ( $p=0.05$ ANOVA) tows. Salps were highest in abundance between 0-50 m outside the eddy (daytime 0.2 ind. $\mathrm{m}^{-3}$ ), 
and generally decreased in abundance with depth (Fig. 10). Despite their patchy depth distribution, salps appear to be migrating more strongly at eddy center vs. outside the eddy. Strength of migration (N:D ratio) for salps at eddy center was 37 times greater (3.7 vs. 0.1) than outside, while amplitude of migration ( $\triangle \mathrm{WMD}$ ) was nearly 17 times greater at eddy center ( $168 \mathrm{~m}$ vs. $10 \mathrm{~m})$ (Table 1$)$.

Of the pelagic gastropods (pteropods and heteropods), heteropods (mostly of the families Atlantidae and Pterotracheidae) were present in relatively low abundance $(<1$ ind. $\mathrm{m}^{-3}$ ), and were more common in eddy center vs. outside (Fig. 11). The pteropods were dominated by Thecosome (shelled) pteropods of the families Limacinidae and Cavoliniidae, and were relatively numerous in surface waters $\left(\sim 10\right.$ ind. $\left.\mathrm{m}^{-3}\right)($ Fig. 11$)$. Gymnosome (shell-less) pteropods were rare at all locations and depths. Pteropods were most abundant in the epipelagic zone and decreased with depth at both locations (Fig. 11 ), yet constituted as much as $20 \%$ of the non-copepod zooplankton community (Fig. 8). Diel vertical migration of pteropods was negligible at eddy center and absent outside the eddy (N:D of 1.1 vs. 0.5 ) and migration amplitude was greater at eddy center vs. outside (75 m vs. $6 \mathrm{~m})$ (Table 1$)$.

Polychaetes, mostly of the families Alciopidae and Tomopteridae, exhibited a mesopelagic peak in abundance in the day, which shoaled at night (Fig. 11). Thus diel vertical migration was pronounced, with $\mathrm{N}: \mathrm{D}$ ratios at center and outside stations of 2.1 and 2.6, respectively (Table 1). Polychaetes also exhibited some of the largest changes in migration amplitude of the taxa sampled ( $87 \mathrm{~m}$ center, $55 \mathrm{~m}$ outside) (Table 1 ). 


\subsection{Changes in zooplankton abundance over time}

This study also provided the unique opportunity to monitor changes in the zooplankton community over the eddy lifecycle, as sampling of these eddies extended over 43-62 days. Total epipelagic zooplankton abundance (between first and last day of sampling) decreased by $\sim 14-56 \%$ (depending on location and time of day) in cyclone

C1 over a period of 43 days, and increased by $\sim 13-250 \%$ (between first and last day of sampling, depending on location and time of day) in mode-water eddy A4 over a period of 62 days. In both eddies we examined in more detail the changes in epipelagic abundance over time for the three most abundant taxonomic groups (total copepods, chaetognaths, and ostracods). In cyclone $\mathrm{C} 1$ decreases in abundance at eddy center for the three groups ranged from $47-60 \%$ (Fig. 12), and decreases at the periphery ranged from 16-62\% (Fig. 12). While slight increases in abundance were noted for chaetognaths and ostracods in daytime tows at eddy periphery, decreases in abundance over time were seen for these two groups in daytime tows at eddy center as well as nighttime tows at periphery stations. It is also important to note that total copepod abundance (which constitutes $75-95 \%$ of total zooplankton abundance in the epipelagic zone) decreased over time at all sampling locations and times of day. Outside eddy stations were not examined as there was a short time span between samples. Conversely, in mode-water eddy A4, abundance of these three groups increased from $20-343 \%$ at eddy center, and remained relatively constant over the duration of sampling outside the eddy (Fig. 13). While slight decreases in abundance were observed for chaetognaths and ostracods in nighttime tows at eddy center, increases in abundance over time were observed in daytime tows at eddy center. Total copepod abundance 
increased during both day and night at eddy center. Total water column abundance (0$700 \mathrm{~m})$ for the three groups tracked epipelagic abundance $(0-150 \mathrm{~m})$ over time in eddy A4 (data not shown).

\subsection{Zooplankton abundance relationship with chlorophyll distribution}

In both eddy $\mathrm{C} 1$ and $\mathrm{A} 4$, the deep chlorophyll maximum fell within the depth range sampled by the 50-100 $\mathrm{m}$ net (usually $\sim 80-90 \mathrm{~m}$ ) (McGillicuddy et al. 2007). Analysis of zooplankton abundance in the centers of eddy A4 and eddy $\mathrm{C} 1$ indicated 4-6 of the 14 broad taxonomic groups sampled (i.e., excluding Pleuromamma spp. copepods and barnacle cyprids) during day and nighttime tows had peak abundances in the 50-100 $\mathrm{m}$ depth interval. Zooplankton sampled during day and nighttime tows outside both eddies also showed elevated abundances in the 50-100 m depth interval ( 5 to 9 of the 14 groups sampled). These included the most numerous herbivorous taxa, the copepods (both inside and outside the eddy). However, there was no significant relationship found between surface-integrated $(0-150 \mathrm{~m})$ zooplankton abundance (by taxonomic group), and surface-integrated $(0-140 \mathrm{~m})$ chlorophyll concentration at any location or sampling time in either eddy (regression $\mathrm{p}>0.05$ ).

\subsection{Comparison with BATS}

\subsubsection{Cyclonic eddy $C 1$}

A comparison of epipelagic zooplankton abundance of the various taxa indicated some significant differences between the BATS site (as an alternative "outside" station) and eddy $\mathrm{C}$. Both non-calanoid copepods and siphonophores had daytime abundances 
at eddy center that were significantly higher $(p=0.02, p=0.04$, respectively ANOVA) than daytime BATS summer mean abundances (Fig. 3, 5). In addition, nighttime chaetognath abundance at eddy center was higher $(p=0.04$ ANOVA) than the nighttime BATS summer mean (Fig. 5). All other taxonomic groups showed no significant ( $p>0.05$ ANOVA) differences between eddy $\mathrm{Cl}$ and BATS (Fig. 3, 4, 5).

Diel vertical migration of about half of the taxa ( 9 of the 16 groups examined) was stronger (higher N:D ratio) at the BATS site than at any location sampled inside or outside eddy $\mathrm{C} 1$ (Table 1,2). Some of the N:D ratio differences between eddy $\mathrm{C} 1$ and BATS were extremely large (euphausiids, hyperiid amphipods, heteropods) (Table 1, 2). However, the $\mathrm{N}$ :D ratio of the most abundant taxonomic group (calanoid copepods) was similar between the eddy and BATS (Table 1,2).

\subsubsection{Anti-cyclonic mode-water eddy $A 4$}

A comparison of epipelagic zooplankton abundance of the various taxa at BATS (June-August, 2005) with mode-water eddy A4 indicates nighttime abundance at eddy center was significantly higher than nighttime abundance at BATS for both calanoid copepods ( $p=0.04$ ANOVA, Fig.3) and chaetognaths ( $p=0.02$ ANOVA, Fig. 5).

Doliolids were also more abundant at eddy center than at BATS for both day $(p=0.03$ ANOVA) and nighttime ( $<00.005$ ANOVA) tows (Fig. 5). Daytime calanoid copepod abundance outside the eddy was significantly higher than daytime abundance at BATS $(p=0.03$ ANOVA) (Fig. 3). Ostracods were the only taxonomic group that had significantly higher abundances ( $\mathrm{p}=0.05$ ANOVA) at BATS during 
daytime tows (Fig. 4). For all other groups, there was no significant ( $p>0.05$ ANOVA) difference between eddy center, outside, and BATS (Fig. 3, 4, 5).

When comparing indices of migration ( $\mathrm{N}$ :D ratio) between the mode-water eddy and BATS, about half ( 9 of the 16) of the taxonomic groups examined were migrating more strongly at eddy center vs. BATS (Table 1,2). Strength of migration at BATS was most similar to the strength of migration outside eddy A4, as 5 of the 16 groups examined had similar N:D ratios (Table 1,2).

\section{Discussion}

\subsection{Zooplankton communities in cyclones vs. mode-water eddies}

Zooplankton community dynamics can be challenging to quantify given the patchiness that exists on various temporal and spatial scales. A suite of biological and physical parameters can influence zooplankton patchiness, including population dynamics, advection, and behavior, all of which can be altered by the presence of mesoscale eddies (Huntley 2000). Despite the considerable difference in both chlorophyll concentration and phytoplankton species composition (McGillicuddy et al. 2007, Bibby et al. in press) between the two eddies, there were few significant differences between eddy types in abundance of the various zooplankton taxa. Goldthwait and Steinberg (in press) also found similar zooplankton biomass in these two eddies. further indicating that both eddy types produced a similar broad zooplankton community response rather than a response from individual taxonomic groups. However, the broad taxonomic categories we used may have disguised changes in abundance of some individual species (see section 4.5 below). 
Mesoscale eddies in the Sargasso Sea form from similar source waters in the northern and eastern regions of the Sargasso Sea and propagate westward (Worthington 1959, Brundage and Dugan 1986, Siegel et al. 1999). Their origin and formation is very different from their analog, Gulf Stream Rings, which form through the pinching off of Gulf Stream meanders, forming either cold core rings with water of continental slope origin at their cores (Parker 1971, Wiebe 1976, Doblar and Cheney 1977, McCartney et al. 1978, Mied and Lindemann 1979, The Ring Group 1981) or warm core rings with water of Sargasso Sea origin at their cores (Csanady 1979, Joyce et al. 1984). Warm core and cold core Gulf Stream Rings support very different zooplankton communities (Wiebe 1976, Wiebe et al. 1976 b, Ortner et al 1978, The Ring Group 1981, Davis and Wiebe 1985, Roman et al. 1985, Wormuth 1985, Beckmann et al. 1987), indicating that the difference in core source water promotes the development of two distinctly different zooplankton communities. In contrast, we suggest the similar Sargasso Sea source waters present at the time of formation of the cyclonic and mode-water eddies in this study entrain and propagate similar zooplankton communities. Increases in abundance, as demonstrated for some of the common taxa in eddy A4, could be attributed to zooplankton enhanced growth and reproduction, as well as their aggregation in areas with high food densities (Huntley et al. 2000). Zooplankton generation times, especially those of the larger taxa, range from weeks (large copepods) to months (euphausiids) (Huntley et al. 2000). The lifespan of mesoscale eddies (several months to a year) may thus provide adequate time for zooplankton to exhibit a reproductive response (Huntley 2000). 
While the abundance of the various taxa in the epipelagic zone was not significantly different between the eddy types, the strength of vertical migration (N:D ratio) was higher for about three quarters of the taxa inside and outside of the mode-water eddy (A4) compared to inside and outside the cyclone (C1). This could be attributed to a difference in availability and type of phytoplankton prey between the two eddies. Higher availability of a more favored food (diatoms) may have caused zooplankton in modewater eddy A4 to migrate more strongly. Similarly, Steinberg et al. (in press a) found stronger diel vertical migration (N:D ratio) in zooplankton sampled at a site dominated by large diatoms (station K2 in the subarctic North Pacific Ocean) as compared to a site dominated by picoplankton and cyanobacteria (station ALOHA in the subtropical North Pacific gyre). Zooplankton migratory behavior has also been shown to be influenced by food availability such that as food availability decreases zooplankton migration amplitudes also decrease (Huntley \& Brooks 1982, Johnsen \& Jakobsen 1987, Lampert 1989). Because food was less limiting at the center of eddy A4 vs. the center of eddy C1, we would expect to see more pronounced (i.e., larger amplitude or N:D ratios) diel vertical migration associated with zooplankton at the center of mode-water eddy A4. However, because more pronounced migratory behavior occurred outside eddy A4 vs. outside $\mathrm{C} 1$ as well, the results can not be attributed solely to the presence of the diatom bloom inside eddy A4, and suggest that interannual differences (i.e., 2004 vs. 2005) in larger-scale Sargasso Sea zooplankton diel migration (e.g., Steinberg et al. 2000) played a role as well. Thus, differences in migratory behavior were not necessarily tied solely to eddy type. 
Although the abundance of different taxa both in and outside the eddy was not significantly correlated with $\mathrm{Chl} a$, it is possible that several physical, chemical, and biological factors (current speed and direction, phytoplankton patchiness, predator abundance, etc.) could be combining to cause a peak in abundance coincident with the Chl $a$ max for many of the taxa. It is also possible that the high variability in zooplankton abundance at eddy center (A4) could be related to the patchy distribution of the central diatom bloom, which was restricted to a small spatial area $(\sim 20-30 \mathrm{~km}$ in diameter) (Bibby et al. in press).

\subsection{General vertical patterns in zooplankton community structure}

\subsubsection{Cyclonic eddy Cl}

The strength of diel vertical migration ( $\mathrm{N}: \mathrm{D}$ ratio) was greater at eddy $\mathrm{Cl}$ center and periphery stations vs. outside eddy stations (excluding BATS). Eleven of the sixteen groups examined had their highest N:D ratios at either center or periphery stations, while only 3 groups (euphausiids, polychaetes, salps) had higher N:D ratios outside the eddy, with non-calanoid copepods and gammarid amphipods having similar N:D ratios across all locations (Table 1). Because zooplankton diel vertical migration tends to be more pronounced in areas of higher food availability (discussed previously), the higher strength of migration observed at the center and periphery of eddy $\mathrm{Cl}$ can likely be attributed to the elevated chlorophyll $a$ values seen inside the eddy (Huntley \& Brooks 1982, Johnsen \& Jakobsen 1987, Lampert 1989). Comparisons with the BATS site indicate highly variable $N: D$ ratios with no distinct pattern of elevated $N: D$ ratios at any sampling 
location (eddy center, periphery, or BATS). Several taxonomic groups within eddy C1 had lower N:D ratios when compared to BATS, however these were the rarer groups with low abundances (e.g., hyperiid and gammarid amphipods, heteropods), thus their N:D ratios will be more variable in space and time.

\subsubsection{Anti-cyclonic mode-water eddy A4}

Both the strength (N:D) and amplitude ( $\triangle \mathrm{WMD}$ ) of migration was higher in eddy A4 center vs. outside and BATS for a number of taxa (calanoid copepods, non-calanoid copepods, ostracods, euphausiids, gammarid amphipods, doliolids, and heteropods), and the N:D ratios outside the eddy more closely resembled those at BATS. Given that $\mathrm{Chl} a$ concentrations were higher at eddy center vs. outside the eddy and at BATS (McGillicuddy et al. 2007, Bibby et al. in press), indicating that food is less limiting at the center vs. outside of eddy A4, as noted above, we may expect to see zooplankton migration behavior be more pronounced at eddy center. Sameoto $(1984,1986)$ also found that regions of elevated primary productivity influenced vertical biomass distributions, as some taxa may preferentially concentrate within the $\mathrm{Chl} a$ maximum. On a more taxon specific level, both Herman (1983) and Castro et al. (1991) found that the dominant calanoid copepod species in their respective study areas tended to aggregate in the deep chlorophyll maximum.

\subsection{General horizontal patterns in zooplankton community structure}

Many taxa in eddy A4 center at night (e.g., calanoid and non-calanoid copepods, doliolids, pteropods and polychaetes) were more abundant than outside the eddy, 
particularly in the epipelagic zone, although the only statistically significant enhancement inside the eddy was in doliolid abundance (both day and night, for the 0-700 $\mathrm{m}$ water column). As mentioned above, elevated nighttime epipelagic abundances at eddy center for many taxa was most likely a result of enhanced zooplankton vertical migration behavior in response to greater food availability. The central region of eddy A4 was exceptional in that it contained the highest primary production rates ever measured at 60 $80 \mathrm{~m}$ relative to the BATS climatology (McGillicuddy et al. 2007). In addition, Goldthwait and Steinberg (2007) measured peak gut fluorescence for the migrating copepod Pleuromamma xiphias, higher fecal pellet carbon flux, and high, but variable, zooplankton biomass at eddy center. The significantly higher doliolid abundance at eddy A4 center vs. outside also suggests a response to improved food conditions within this eddy. Doliolids can reproduce asexually, allowing them to rapidly reproduce and form blooms in response to improved food conditions (Deibel 1985, 1998, Gibson and Paffenhoffer 2002). While eddy A4 did persist long enough (several months) to allow sufficient time for other groups of zooplankton to reproduce, doliolids are particularly well suited for taking advantage of the rapid-onset diatom bloom seen in eddy A4.

Landry et al. (in press b) saw similar changes in zooplankton biomass without significant changes in abundance of individual taxa of zooplankton studied in a diatomdominated cyclonic eddy in the lee of the Hawaiian Islands. The authors also propose a broad zooplankton community increase in the area perturbed by the cyclone, as opposed to specific taxonomic differences between sampling locations inside and outside of the eddy. 
Goldthwait and Steinberg`s (in press) analysis of zooplankton biomass from these two eddies indicates that zooplankton samples from the BATS site were a more representative outside eddy station, and that when compared with BATS, both eddies had significantly ( $<<0.05$ ANOVA) higher biomass (center and periphery). Abundances of calanoid copepods (A4 night), non-calanoid copepods ( $\mathrm{C} 1$ day), chaetognaths (C1/A4 night), doliolids (A4 night, day) and siphonophores ( $\mathrm{C} 1$ day) were significantly higher at eddy center vs. BATS (as an outside station). However, for all other taxonomic groups examined, there was no significant elevation of abundance eddy center versus outside or BATS for either sampling year. For most taxonomic groups in this study, the standard deviations of the zooplankton abundances at BATS were much smaller than at center and outside stations in eddy A4. This suggests that the BATS site is a more stable environment, and that the eddy stations were subject to a greater amount of physical, chemical, and biological variability due to the influence of the eddy. Therefore, our data also indicate that BATS may be a more representative "outside eddy" station than the stations noted as outside stations, which may have been under the influence of the eddy, or were influenced by other eddies (eddy-eddy interaction).

Eddy lifecycle also plays an important role in the distribution of zooplankton. Mode-water eddy A4 was still in a "bloom phase" and macronutrients were being consistently supplied to the surface waters through upwelling for the entire duration of sampling (June-August) (McGillicuddy et al. 2007, Ledwell et al. in press, Li and Hansell in press). Conversely, cyclonic eddy $\mathrm{Cl}$ was in a "decay phase" over the duration of the sampling period, as evidenced by decreased strength of upwelling, changes from a local maximum to a local minimum of chlorophyll $a$ at eddy center, as well as an altimetric 
history that suggested intensification in May, prior to the first occupation of this eddy (McGillicuddy et al. 2007). The contrasting phases of the two eddies are further supported by the temporal trends in zooplankton abundance in these two features. Decreases in epipelagic abundance over a $\sim 1$ month period of the three most abundant taxa (total copepods, chaetognaths, ostracods) in eddy $\mathrm{C} 1$ indicate zooplankton were being negatively affected by the "decay phase" portion of eddy $\mathrm{C} 1$ 's lifecycle. Conversely, increases in epipelagic abundance over a $\sim 2$ month period of the same three most abundant taxa in eddy A4 suggest the zooplankton community was responding to the sustained, high levels of macronutrients being supplied to the surface waters through upwelling and the resultant diatom bloom. Goldthwait and Steinberg (in press) saw similar results in their analysis of zooplankton biomass over the same time interval in both of these eddies. Most notably, zooplankton biomass was elevated throughout the summer in eddy A4, while zooplankton biomass reached a peak in late June and decreased slowly throughout the remainder of the summer sampling period in eddy $\mathrm{Cl}$.

\subsection{Potential for transport and aggregation of zooplankton}

Barnacle cyprids found at depth $(200-700 \mathrm{~m})$ in both eddies indicate the potential for these eddies to act as a transport and dispersal mechanism for larvae of all types. Lepas pectinata is a common North Atlantic barnacle found in the Sargasso Sea, where the adults are most commonly found associated with floating debris, especially Sargassum spp. seaweed (Moyse 1987). Little is known about the life history of this species of barnacle; however Conway et al. (1990) observed similar depth distribution patterns, and abundance of $L$. pectinata cyprids in zooplankton tows from the Sargasso 
Sea near Bermuda, as well as in the Azores frontal region of the North Atlantic Ocean. Cyprids were abundant both inside and outside the eddies, indicating that their mesopelagic distribution is a widespread phenomenon rather than an eddy-induced effect. Conway et al. (1990) propose the most likely explanation for this depth distribution in colder, deeper waters is that this is an ontogenetic migration designed to reduce metabolism and extend life expectancy for settlement and metamorphosis to adulthood in a more favorable time of year. Entrainment and transport within these eddies would presumably be beneficial to the barnacles, providing the surface-feeding larval stages (nauplii) with a higher, consistent food source in the epipelagic zone, as well as providing the non-feeding larval stages (cyprids) in the mesopelagic zone with greater dispersal potential, as opposed to larvae outside the eddies. Megalops of hermit crabs (Pagurus sp.) were also present in surface samples $(0-150 \mathrm{~m})$ of cyclone $\mathrm{C} 1$, and in 2004 summer samples from the BATS site, and were rare in eddy A4 and 2005 BATS samples. Like the barnacle cyprids found in both eddies, hermit crab larvae in C1 may also benefit from entrainment within the eddy.

\subsection{Sampling considerations}

While we conducted a significant number of MOCNESS tows in order to obtain sufficient replication, there was still considerable variability in the data. Zooplankton abundance can fluctuate considerably over small temporal and spatial scales (Angel et al. 1982. Angel and Pugh 2000); thus, it is conceivable that by the time our nets reached the surface, the ship may have drifted out of the patch of zooplankton we were sampling at depth. Another consideration is the broad taxonomic groups we used to characterize 
zooplankton abundance, which likely limited our ability to resolve spatial differences within each eddy as well as differences between eddy types. Given that there are over 326 species of copepods (all orders, 0-2000 m) found in the Sargasso Sea near Bermuda (Deevey and Brooks 1977), as well as considerable diversity found in most other taxonomic groups (Deevey 1971, Deevey and Brooks 1971), a species-level focus, although time-intensive, would elucidate some of the factors contributing to the high variability in abundance of major taxa. In addition to inherent variability in the data set, there are a number of potential errors associated with estimating abundance and biomass of zooplankton with nets (Angel and Pugh 2000). These include underestimation of fragile or patchy gelatinous zooplankton, daytime net avoidance, vertical migration to depths deeper than the lowest sampling depth, and the inherent patchiness of plankton communities due to passive or active aggregation and rapid reproduction and growth (Steinberg et al. in press a). While several gelatinous taxa such as siphonophores, chaetognaths, and polychaetes were well represented in our samples, groups such as larvaceans, and hydrozoan medusae were not. Larvaceans are common in summer at BATS (pers. obs.), and hydrozoan medusae were abundant in separate surface tows taken during this study. These groups were likely destroyed beyond recognition. especially in our deeper nets in the MOCNESS (Steinberg et al. in press a). Furthermore, other taxa such as bloom-forming salps are patchy (Madin et al. 2006) and could be missed (Angel and Pugh 2000, Roman et al. 2002). Daytime net avoidance appears negligible in our study, with a $\sim 6 \%$ increase in $0-700 \mathrm{~m}$ integrated abundance at night vs. day at A4 eddy center. Lastly, patchiness of phytoplankton in both eddies sampled (McGillicuddy et al. 
2007, Bibby et al. in press) could have led to patchiness of zooplankton, resulting in variable abundance.

\subsection{Potential eddy effects on biogeochemical cycling in the Sargasso Sea}

Eddy-mediated changes in zooplankton community structure could have important implications for the functioning of oligotrophic food webs, the transfer of particulate organic matter to depth, and affect carbon sequestration in the deep ocean (Buesseler et al. in press, Goldthwait \& Steinberg in press, Steinberg et al. in press b, Verdeny et al. in press). Food webs in oligotrophic gyres are primarily recycling pathways where little material is lost from the system through sinking (Landry et al. 1995). Sustained presence of elevated macronutrient levels particularly in eddy A4 (Li \& Hansell in press) resulted in a shift to larger phytoplankton species, which in turn is predicted to favor an export food web dominated by larger zooplankton (Michaels \& Silver 1988, Legendre \& Le Fevre 1995). Larger zooplankton export C to depth via production of sinking fecal pellets (Fowler \& Knauer 1986, Small et al. 1989, Altabet \& Small 1990) and active transport during diel vertical migrations whereby $\mathrm{C}$ is consumed in surface waters and metabolized (i.e., respired, excreted, or egested) at depth (Longhurst et al. 1990, Al-Mutairi \& Landry 2001, Steinberg et al. 2000).

There is some evidence to support a shift toward an export-dominated food web in eddy A4 as we saw increases in zooplankton abundance over time at eddy center, coupled with elevated diel vertical migration at eddy center, and elevated copepod and doliolid abundances relative to the BATS summer mean. Furthermore, Goldthwait and Steinberg (in press) saw increased fecal pellet flux (dominated by large euphausiid 
pellets) in the interiors of both eddies as well as enhanced active carbon transport by diel vertical migration at the periphery (cyclone) and center (mode-water eddy) over the BATS summer mean (1994-2005). Increases in active carbon transport have also been observed in a cyclonic eddy near Hawaii (Landry et al. in press b), and an anticyclonic eddy near the Canary Islands (Yebra et al. 2005). The elevated abundance of zooplankton, coupled with enhanced fecal pellet production and stronger diel vertical migration of many taxa at eddy center, would thus increase the efficiency of the biological pump in waters under eddy influence.

\section{Summary and Conclusion}

We found the abundance of a number of broad taxonomic groups was similarly enhanced in a cyclonic eddy and an anti-cyclonic mode-water eddy sampled in the Sargasso Sea in the summers of 2004 and 2005. In addition, daytime and nighttime zooplankton community structure (abundance percent composition) in the two eddies was similar at all locations sampled. There were two main differences between the two eddy types. The strength of diel vertical migration was higher in the mode-water eddy than in the cyclone. We also saw a decrease in abundance of the most common taxa over time in the cyclone, in contrast to an increase in the mode-water eddy. While peak abundance for a number of taxa was in the 50-100 m depth interval, coincident with the deep chlorophyll maximum, no significant relationship was found between integrated chlorophyll concentration and zooplankton abundance in either eddy. The similar enhancement of the zooplankton communities inside these two eddies as compared to outside stations suggests sustained, widespread changes in the total zooplankton 
community rather than an immediate response of just a few individual taxa to eddy influence. This is consistent with mesoscale eddies being long-lived, relatively stable features that are capable of producing elevated macronutrient concentrations over a sustained time period, thus stimulating long-lived phytoplankton blooms (Bibby et al. in press). Eddy-mediated changes in zooplankton community structure and behavior can increase the efficiency of the biological pump in oligotrophic systems. The complex dynamics in these common, yet highly variable mesoscale features thus can influence and regulate zooplankton community structure and biogeochemical cycling in the Sargasso Sea. 


\section{Literature Cited}

Al-Mutairi. H., Landry, M. R.. 2001. Active export of carbon and nitrogen at Station ALOHA by diel migrant zooplankton. Deep Sea Research II 48, 2083-2103.

Altabet, M. A., Small, L. F., 1990. Nitrogen isotopic ratios in fecal pellets produced by marine zooplankton. Geochimica et Cosmochimica Acta 54, 155-163.

Andersen, V., Devey, C., Gubanova, A., Picheral, M., Melnikov, V., Tsarin. S., Prieur, L., 2004. Vertical distributions of zooplankton across the Almeria-Oran frontal zone (Mediterranean Sea). Journal of Plankton Research 26, 275-293.

Andersen, V., Gubanova, A., Nival, P., Ruellet, T., 2001. Zooplankton community during the transition from spring bloom to oligotrophy in the open $\mathrm{NW}$ Mediterranean and effects of wind events. 2. Vertical distributions and migrations. Journal of Plankton Research 23, 243-261.

Andersen, V., Sardou, J., Gasser, B., 1997. Macroplankton and micronekton in the northeast tropical Atlantic: abundance, community composition and vertical distribution in relation to different trophic environments. Deep Sea Research I 44, 193-222.

Angel, M. V., Fasham, M. J. R., 1983. Eddies and biological processes. In Robinson, A. (Ed.), Eddies in Marine Science. Springer-Verlag, New York, NY, Chapter 22.

Angel, M. V., Hargreaves, P., Kirkpatrick, P., Domanski, P., 1982. Low Variability in Planktonic and Micronektonic Populations at 1,000 m Depth in the Vicinity of 42 N. 17 W; Evidence Against Diel Migratory Behavior in the Majority of Species. Biological Oceanography 1, 287-318.

Angel, M. V., Pugh, P. R., 2000. Quantification of diel vertical migration by micronektonic taxa in the northeast Atlantic. Hydrobiologia 440, 161-179.

Arashkevich, E. G., Drits. A. V., Timonin. A. G., Kremenetskiy, V. V., 2002. Variability of spatial zooplankton distribution affected by the water dynamics in the northeastern part of the Black Sea. Oceanology 42, S79-S94.

Batten S. D., Crawford, W. R.. 2005. The influence of coastal origin eddies on oceanic plankton distributions in the eastern Gulf of Alaska. Deep Sea Research II 52, 991-1009.

Beckmann, W., Auras, A., Hemleben, C., 1987. Cyclonic cold-core eddy in the eastern North Atlantic. III. Zooplankton. Marine Ecology Progress Series 39, 165-173. 
Benitez-Nelson, C. R., Bidigare, R. R., Dickey, T. D., Landry, M. R., Leonard, C. L., Brown, S. L., Nencioli, F., Rii, Y. M., Maiti, K., Becker, J. W., Bibby, T. S., Black, W., Cai, W. J., Carlson, C. A., Chen, F., Kuwahara, V. S, Maharrey, C., McAndrew, P. M., Quay, P. D., Rappe', M. S., Selph, K. E., Simmons, M. P., Yang, E. J., 2007. Mesoscale Eddies Drive Increased Silica Export in the Subtropical Pacific Ocean. Science 316, 1017-1021.

Bibby, T. S., Gorbunov, M.Y., Wyman, K. W., Falkowski, P. G., in press. Photosynthetic community responses to upwelling mesoscale eddies in the subtropical north Atlantic and Pacific Oceans. Deep Sea Research II.

Boyd, S. H., Wiebe, P. H., Cox, J. L., 1978. Limits of Nematoscelis megalops in the Northwestern Atlantic in relation to Gulf Stream cold core rings. II.

Physiological and biochemical effects of expatriation. Journal of Marine Research 36, 143-159.

Brundage, W. L., Dugan, J. P., 1986. Observations of an Anticyclonic Eddy of $18^{\circ} \mathrm{C}$ Water in the Sargasso Sea. Journal of Physical Oceanography 16, 717-727.

Bucklin, A., 1991. Population Genetic Responses of the Planktonic Copepod Metridia pacifica to a Coastal Eddy in the California Current. Journal of Geophysical Research 96, 799-808.

Buesseler, K. O., Lamborg, C., Cai, P., Escoube, R., Johnson, R., Pike, S., Masque, P, McGillicuddy, D. J., Verdeny, E., in press. Particle fluxes associated with mesoscale eddies in the Sargasso Sea. Deep Sea Research II.

Castro, L. R., Bernal, P. A., Gonzalez, H. E., 1991. Vertical distribution of copepods and the utilization of the chlorophyll a-rich layer within Concepcion Bay, Chile. Estuarine, Coastal and Shelf Science 32, 243-256.

Conway, D. V. P., Ellis, C. J., Humpheryes, I. G., 1990. Deep distributions of oceanic cirripede larvae in the Sargasso Sea and surrounding North Atlantic Ocean. Marine Biology 105, 419-428.

Csanady, G. T., 1979. The Birth and Death of a Warm Core Ring. Journal of Geophysical Research 84, 777-780.

Davis, C. S., Wiebe, P. H., 1985. Macrozooplankton Biomass in a Warm-Core Gulf Stream Ring: Time Series Changes in Size Structure, Taxonomic Composition, and Vertical Distribution. Journal of Geophysical Research 90, 8871-8884.

Deevey, G. B., 1971. The annual cycle in quantity and composition of the zooplankton of the Sargasso Sea off Bermuda. I. The upper $500 \mathrm{~m}$. Limonology and Oceanography 16, 219-240. 
Deevey, G. B., Brooks, A. L., 1971. The annual cycle in quantity and composition of the zooplankton of the Sargasso Sea off Bermuda. II. The surface to $2000 \mathrm{~m}$. Limnology and Oceanography 16, 927-943.

...1977. Copepods of the Sargasso Sea off Bermuda: Species Composition, and Vertical and Seasonal Distribution Between the Surface and $2000 \mathrm{~m}$. Bulletin of Marine Science 27, 256-291.

Deibel, D., 1985. Blooms of the pelagic tunicate, Dolioletta gegenbauri: Are they associated with Gulf Stream frontal eddies? Journal of Marine Research 43, 211 236.

...1998. The abundance, distribution and ecological impacts of doliolids. In Bone, Q. (ed.). The Biology of Pelagic Tunicates. Oxford University Press, Oxford. 171-186.

Dickey, T., Nencioli, F., Kuwahara, V., Leonard, C., Black, W., Bidigare, R., Rii, Y., Zhang, Q., in press. Physical and Bio-optical Observations of Oceanic Cyclones West of the Island of Hawaii. Deep Sea Research II.

Doblar, R. A., Cheney, R. E., 1977. Observed formation of a Gulf Stream cold-core ring. Journal of Physical Oceanography 7, 944-946.

Ewart, C. S., Meyers, M. K., Wallner, E., McGillicuddy Jr., D. J., Carlson, C. A., in press. Microbial Dynamics in Cyclonic and Anticyclonic Mode-Water Eddies in the Northwestern Sargasso Sea. Deep Sea Research II.

Fowler, S. W., Knauer, G. A., 1986. Role of large particles in the transport of elements and organic compounds through the oceanic water column. Progress in Oceanography 16, 147-194.

Gibson, D. M.. Paffenhofer, G.A., 2002. Asexual reproduction of the doliolid, Dolioletta gegenbauri Uljanin (Tunicata, Thaliacea). Journal of Plankton Research 24, 703712

Goldthwait, S. A., Steinberg, D. K., in press. Elevated Biomass of Mesozooplankton and Enhanced Fecal Pellet Flux in Cyclonic and Mode-Water Eddies in the Sargasso Sea. Deep Sea Research II.

Haury, L. R., 1984. An Offshore Eddy in the California Current System. Part IV: Plankton Distributions. Progress in Oceanography 13, 95-111.

Herman, A. W., 1983. Vertical Distribution Patterns of Copepods, Chlorophyll, and Production in Northeastern Baffin Bay. Limnology and Oceanography 28, 709719. 
Hernandez-Leon, S., Almeida, C., Gomez, M., Torres, S., Montero, I., PortilloHahnefeld, A., 2001. Zooplankton biomass and indices of feeding and metabolism in island-generated eddies around Gran Canaria. Journal of Marine Systems 30, 51-66.

Hitchcock, G. L., Langdon, C., Smayda, T. J., 1985. Seasonal variations in the phytoplankton biomass and productivity of a warm-core Gulf Stream ring. Deep Sea Research I 32, 1287-1300.

Huntley, M. E., Brooks, E. R., 1982. Effects of Age and Food Availability on Diel Vertical Migration of Calanus pacificus. Marine Biology 71, 23-31.

Huntley, M. E., Gonzales, A., Zhu, Y., Irogoien, X., 2000. Zooplankton dynamics in a mesoscale eddy-jet system off California. Marine Ecology Progress Series 201, $165-178$.

Jenkins, W. J., Goldman, J. C., 1985. Seasonal oxygen cycling and primary production in the Sargasso Sea. Journal of Marine Research 43, 465-491.

Johnsen, G. H., Jakobson, P. J., 1987. The Effect of Food Limitation on Vertical Migration in Daphnia longispina. Limnology and Oceanography 32, 873-880.

Joyce, T. M., Backus, R., Baker, K., Blackwelder, P., Brown, O., Cowles, T., Evans, R., Fryxell, G., Mountain, D., Olson, D., Schlitz, R., Schmitt, R., Smith, P., Smith, R., Wiebe, P., 1984. Rapid evolution of a Gulf Stream warm-core ring. Nature $308,837-840$.

Lampert, W., 1989. The Adaptive Significance of Diel Vertical Migration of Zooplankton. Functional Ecology 3, 21-27.

Landry, M. R., Al-Mutairi, H., Selph, K.E., Christensen, S., Nunnery, S., 2001. Seasonal patterns of mesozooplankton abundance and biomass at Station ALOHA. Deep Sea Research II 48, 2037-2061.

Landry, M. R., Brown, S. L., Rii, Y. M., Selph, K. E., Bidigare, R. R., Yang, E. J., Simmons, M. P., in press ${ }^{b}$. Depth-stratified phytoplankton dynamics in Cyclone Opal, a subtropical mesoscale eddy. Deep Sea Research II.

Landry, M. R., Decima, M., Simmons, M. P., Hannides, C. C. S., Daniels, E., in press ${ }^{\mathrm{a}}$. Mesozooplankton biomass and grazing responses to Cyclone Opal, a subtropical mesoscale eddy. Deep Sea Research II.

Landry, M. R., Peterson, W. K., Lorenzen, C. J., 1995. Zooplankton grazing, phytoplankton growth, and export flux: inferences from chlorophyll tracer methods. ICES Journal of Marine Science 52, 337-345. 
Ledwell, J. R., McGillicuddy, D. J., Anderson, L. A., in press. Nutrient flux into an intense deep chlorophyll layer in a mode-water eddy. Deep Sea Research II.

Legendre, L., Le Fevre, J., 1995. Microbial food webs and the export of biogenic carbon in oceans. Aquatic Microbial Ecology 9, 69-77.

Li, Q. P., Hansell, D. A., in press. Interaction of nutrients and chlorophyll biomass in baroclinic eddies of the oligotrophic North Atlantic. Deep Sea Research II.

Longhurst, A. R., Bedo, A. W., Harrison, W. G., Head, E. J. H., Sameoto, D. D., 1990. Vertical flux of respiratory carbon by oceanic diel migrant biota. Deep Sea Research I 37, 685-694.

Lutjeharms, J. R. E., Valentine, H. R., 1988. Eddies at the Sub-Tropical Convergence south of Africa. Journal of Physical Oceanography 18, 761-774.

Mackas, D. L.. Galbraith, M. D., 2002. Zooplankton distribution and dynamics in a North Pacific eddy of coastal origin: 1. Transport and loss of continental margin species. Journal of Oceanography 58, 725-738.

Mackas, D. L.. Tsurumi, M., Galbraith, M. D., Yelland, D. R., 2005. Zooplankton distribution and dynamics in a North Pacific Eddy of coastal origin: II. Mechanisms of eddy colonization by and retention of offshore species. Deep Sea Research II 52, 1011-1035.

Madin, L. P., Horgan, E. F., Steinberg, D. K., 2001. Zooplankton at the Bermuda Atlantic Time-series Study (BATS) station: diel, seasonal, and interannual variation in biomass, 1994-1998. Deep Sea Research II 48, 2063-2082.

Madin, L. P., Kremer, P., Wiebe, P. H., Purcell, J. E., Horgan, E. H., Nemazie, D. A., 2006. Periodic swarms of the salp Salpa aspera in the Slope Water off the NE United States: Biovolume, vertical migration, grazing, and vertical flux. Deep Sea Research I 53, 804-819.

Mann, K., Lazier, J., 1991. Dynamics of Marine Ecosystems, Blackwell Scientific Publications, Oxford.

McAndrew, P. M., Bidigare, R. R., Karl, D. M., in press. Primary production and implications for metabolic balance in Hawaiian lee eddies. Deep Sea Research II.

McCartney, M. S., Worthington, L. V., Schmitz, W. J. J., 1978. Large Cyclonic Rings From the Northeast Sargasso Sea. Journal of Geophysical Research 83, 901-919.

McGillicuddy Jr., D. J., 2001. The Internal Weather of the Sea and Its Influences on Ocean Biogeochemistry. Oceanography 14, 74-89. 
McGillicuddy Jr., D. J., Anderson, L. A., Bates, N. R., Bibby, T., Buesseler, K. O., Carlson, C. A., Davis, C. S., Ewart. C., Falkowski, P. G., Goldthwait, S. A., Hansell, D. A., Jenkins, W. J., Johnson, R., Kosnyrev, V. K., Ledwell, J. R., Li, Q. P., Siegel, D. A., Steinberg, D. K., 2007. Eddy/wind interactions stimulate extraordinary mid-ocean plankton blooms. Science 316, 1021-1026.

McGillicuddy, D. J., Robinson, A. R., 1997. Eddy-induced nutrient supply and new production in the Sargasso Sea. Deep Sea Research I 44, 1427-1450.

McGillicuddy D. J., Robinson, A. R., Siegel, D. A., Jannasch, H. W., Johnson, R., Dickey, T. D., McNeil, J., Michaels, A. F., Knap, A. H., 1998. Influence of mesoscale eddies on new production in the Sargasso Sea. Nature 394, 263-266.

McNeil, J. D., Jannasch, H. W., Dickey, T., McGillicuddy, D. J., Brzezinski, M., Sakamoto, C., 1999. New chemical, bio-optical and physical observations of upper ocean response to the passage of a mesoscale eddy off Bermuda. Journal of Geophysical Research 104, 15537-15548.

Michaels, A. F., 1995. Ocean Time Series Research Near Bermuda: The Hydrostation S Time Series and the Bermuda Atlantic Time-Series Study (BATS) Program. In Powell, T. M., Steele, J. H. (Eds.), Ecological Time Series. Chapman and Hall, New York, NY, 181-208.

Michaels, A. F., Silver, M. W., 1988. Primary production, sinking fluxes and the microbial food web. Deep Sea Research I 35, 473-490.

Mied, R. P., Lindemann, G. J., 1979. The propagation and evolution of cyclonic Gulf rings. Journal of Physical Oceanography 9, 1183-1206.

Mourino-Carballido, B., Mcgillicuddy, D., 2006. Mesoscale variability in the metabolic balance of the Sargasso Sea. Limnology and Oceanography 51, 2675-2689.

Moyse, J., 1987. Larvae of lepadomorph barnacles. In Southward, A. J. (Ed.), Barnacle Biology. A. A. Balkema, Rotterdam, 329-357.

Olson, D., 1991. Rings in the ocean. Annual Review of Earth and Planetary Science 19, 283-311.

Ortner, P. B., Wiebe, P. H., Haury, L., Boyd, S. H., 1978. Variability in zooplankton biomass distribution in the Northern Sargasso Sea: The contribution of Gulf Stream cold core rings. Fishery Bulletin 76, 323-334.

Oschiles, A., Garcon, V., 1998. Eddy-induced enhancement of primary production in a model of the North Atlantic Ocean. Nature 394, 266-269. 
Owen, R., 1981. Fronts and eddies in the sea: mechanisms, interactions, and biological effects. In Longhurst, A. R. (Ed.), Analysis of Marine Ecosystems. Academic Press, London, 197-233.

Pakhomov, E. A., Perissinotto, R., 1997. Mesozooplankton community structure and grazing impact in the region of the subtropical convergence south of Africa. Journal of Plankton Research 19, 675-691.

Parker, C. E.. 1971. Gulf Stream rings in the Sargasso Sea. Deep Sea Research I 18, 981-993.

Piontkovski, S. A., Williams, R., Peterson, W., Kosnirev, V. K., 1995. Relationship between oceanic mesozooplankton and energy of eddy fields. Marine Ecology Progress Series 128, 35-41.

Roman, M. R., Adolf, H. A., Landry, M. R., Madin, L. P., Steinberg, D. K., Zhang, X., 2002. Estimates of oceanic mesozooplankton production: a comparison using Bermuda and Hawaii time-series data. Deep Sea Research 11 49, 175-192.

Roman, M. R., Gauzens, A. L.. Cowles, T. J., 1985. Temporal and spatial changes in epipelagic microzooplankton and mesozooplankton biomass in warm-core Gulf Stream ring 82-B. Deep Sea Research I 32, 1007-1022.

Sameoto, D. D., 1984. Environmental factors influencing diurnal distribution of zooplankton and ichthyoplankton. Journal of Plankton Research 6, 767-792.

...1986. Influence of the biological and physical environment on the vertical distribution of mesozooplankton and micronekton in the eastern tropical Pacific. Marine Biology 93, 263-269.

Scott, B. D., 1981. Hydrological Structure and Phytoplankton Distribution in the Region of a Warm-core Eddy in the Tasman Sea. Australian Journal of Marine and Freshwater Research 32, 479-492.

Siegel, D. A., McGillicuddy, D. J., Fields, E. A., 1999. Mesoscale eddies, satellite altimetry, and new production in the Sargasso Sea. Journal of Geophysical Research 104, 13359-13379.

Small, L. F, Landry, M. R., Eppley, R. W., Azam, F., Carlucci, A. F.. 1989. Role of plankton in the carbon and nitrogen budgets of Santa Monica Basin. California. Marine Ecology Progress Series 56, 57-74.

Steinberg, D. K., Carlson. C. A., Bates, N. R., Goldthwait, S. A., Madin, L. P., Michaels, A. F., 2000. Zooplankton vertical migration and the active transport of dissolved organic and inorganic carbon in the Sargasso Sea. Deep Sea Research I 47, 137 158. 
Steinberg, D. K., Cope, J. S., Wilson, S. E., Kobari, T., in press. ${ }^{a}$ A comparison of mesopelagic mesozooplankton community structure in the subtropical and subarctic north Pacific Ocean. Deep Sea Research II.

Steinberg, D. K., Van Mooy, B. A. S., Buesseler, K. O., Boyd, P. W., Kobari , T., Karl, D. M., in press ${ }^{b}$. Bacterial vs. zooplankton control of sinking particle flux in the ocean's twilight zone. Limnology and Oceanography.

Sweeney, E. N., McGillicuddy, D .J., Buesseler, K. O., 2003. Biogeochemical impacts due to mesoscale eddy activity in the Sargasso Sea as measured at the Bermuda Atlantic Time-series Study (BATS). Deep Sea Research II 50, 3017-3039.

The Ring Group, 1981. Gulf Stream Cold-Core Rings: Their Physics, Chemistry, and Biology. Science 212, 1091-1100.

Tranter, D. J., Leech, G. S., Airey, D., 1983. Edge Enrichment in an Ocean Eddy. Australian Journal of Marine and Freshwater Research 34, 665-680.

Tsurumi, M., Mackas, D. L., Whitney, F. A., DiBacco, C., Galbraith, M. D., Wong, C. S., 2005. Pteropods, eddies, carbon flux, and climate variability in the Alaska Gyre. Deep Sea Research II 52, 1037-1053.

Verdeny, E., Masque', P., Maiti, K., Garcia-Orellana, J., Bruach, J. M., Mahaffey, C., Benitez-Nelson, C. R., in press. Particle Export within cyclonic Hawaiian lee eddies derived from ${ }^{210} \mathrm{~Pb}-{ }^{210} \mathrm{Po}$ disequilibria. Deep Sea Research II.

Wiebe, P. H., 1982. Rings of the Gulf Stream. Scientific American 246, 50-60.

Wiebe, P. H., Burt, K. H., Boyd, S. H., Morton, A. W., 1976a . A multiple opening/closing net and environmental sensing system for sampling zooplankton. Journal of Marine Research 34, 313-326.

Wiebe, P. H., Hulburt, E. M., Carpenter, E. J., Jahn, A. E., Knapp, G. P., Boyd, S. H., Ortner, P. B., Cox, J. L., 1976 ${ }^{\mathrm{b}}$. Gulf Stream cold core rings: large-scale interaction sites for open ocean plankton communities. Deep Sea Research I 23, 695-710.

Wormuth, J. H., 1985. The role of cold-core Gulf Stream rings in the temporal and spatial patterns of euthecosomatous pteropods. Deep Sea Research I 32, 773-788.

Worthington, L. V., 1959. The 18 degree water in the Sargasso Sea. Deep Sea Research I 5, 297-305.

Yebra, L., Almedia, C., Leon-Hernandez, S., 2005. Vertical distribution of zooplankton and active flux across an anticyclonic eddy in the Canary Island waters. Deep Sea Research I 52, 69-83. 
Table 1. Diel vertical migration indices for major taxa of zooplankton in $\mathrm{C} 1$ and $\mathrm{A} 4$. $\mathrm{N}: \mathrm{D}$ ratio - Ratio of night:day taxon abundance integrated over the surface $0-150 \mathrm{~m}$. Ratio was computed after abundance values were averaged across all tows at each location. WMD - Weighted mean depth for day and night (see methods). $\triangle$ WMD Amplitude of the migration, calculated as day WMD minus night WMD. Dash (-) indicates not determined (see footnote for explanation). Sample size, n, (day/night) is indicated at head of each column.

\begin{tabular}{|c|c|c|c|}
\hline Eddy and taxon & $\begin{array}{c}\text { Center } \\
N: D \\
\text { ratio in } \\
\text { surface } \\
150 \mathrm{~m}\end{array}$ & $\begin{array}{c}\text { Periphery } \\
\mathrm{N}: \mathrm{D} \text { ratio } \\
\text { in } \\
\text { surface } \\
150 \mathrm{~m} \\
\end{array}$ & $\begin{array}{c}\text { Outside } \\
\mathrm{N}: \mathrm{D} \text { ratio } \\
\text { in } \\
\text { surface } \\
150 \mathrm{~m}\end{array}$ \\
\hline CYCLONE C1 & $n=2 / 2$ & $n=2 / 2$ & $n=1 / 1$ \\
\hline Calanoid copepods & 0.8 & 0.7 & 0.4 \\
\hline Pleuromamma spp. & 26.2 & 98.2 & 22.6 \\
\hline Non-calanoid copepods & 0.6 & 0.6 & 0.7 \\
\hline Ostracods & 1.9 & 0.8 & 0.9 \\
\hline Decapods & 1.7 & 2.3 & $<0.1$ \\
\hline Euphausiids & 3.4 & 2.7 & 4.4 \\
\hline Hyperiid amphipods & 3.3 & 0.9 & 1.2 \\
\hline Gammarid amphipods & $-{ }^{a}$ & $-a^{a}$ & $-{ }^{a}$ \\
\hline Chaetognaths & 1.2 & 0.8 & 1.0 \\
\hline Siphonophores & 0.3 & 0.4 & 0.1 \\
\hline Doliolids & 1.4 & 0.7 & 0.3 \\
\hline Salps & $-{ }^{a}$ & 0.3 & 5.5 \\
\hline Pteropods & 0.7 & 1.6 & 0.2 \\
\hline Heteropods & 0.1 & 1.4 & $<0.1$ \\
\hline Polychaetes & 1.0 & 1.3 & 1.3 \\
\hline Barnacle Cyprids & $-b$ & $-{ }^{b}$ & $-b$ \\
\hline
\end{tabular}

a either did not occur in 0-150 m layer in day (i.e., N:D undefined) or at night (i.e., N:D = $0),{ }^{b}$ did not occur. 


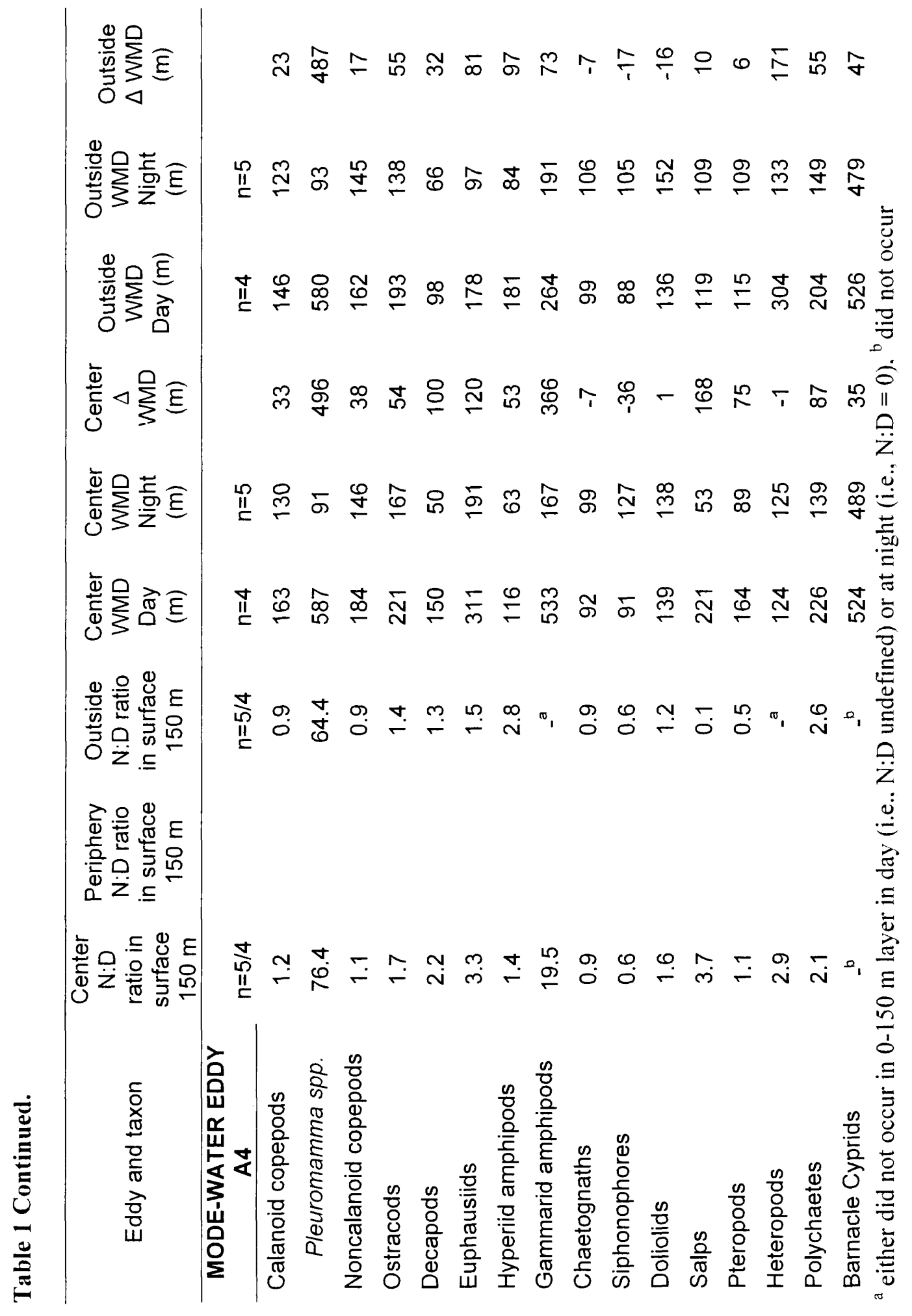


Table 2. Diel vertical migration indices for major taxa of zooplankton at BATS. N:D ratio - Ratio of night:day taxon abundance integrated over the surface $0-150 \mathrm{~m}$. Ratio was computed after abundance values were averaged across all tows at each location. Dash (-) indicates not determined (see footnote for explanation). Sample size, $n$, (day/night) is indicated at head of each column.

\begin{tabular}{lcc}
\hline Location and taxon & $\begin{array}{c}\mathrm{N}: \mathrm{D} \\
\text { ratio in } \\
\text { surface } \\
150 \mathrm{~m}\end{array}$ & $\begin{array}{c}\mathrm{N}: \mathrm{D} \\
\text { ratio in } \\
\text { surface } \\
150 \mathrm{~m}\end{array}$ \\
\hline \multicolumn{1}{c}{ BATS Summer Mean } & $\mathbf{2 0 0 4}$ & $\mathbf{2 0 0 5}$ \\
$\mathrm{n}=5 / 6$ & $\mathrm{n}=6 / 6$ \\
Calanoid copepods & 1.0 & 1.0 \\
$\quad$ Pleuromamma spp. & $-\mathrm{a}$ & $-{ }^{\mathrm{a}}$ \\
Noncalanoid copepods & 1.3 & 0.9 \\
Ostracods & 1.1 & 1.2 \\
Decapods & 1.5 & 2.2 \\
Euphausiids & 55.1 & 0.5 \\
Hyperiid amphipods & 93.5 & 1.1 \\
Gammarid amphipods & 9.6 & 0.9 \\
Chaetognaths & 0.5 & 0.8 \\
Siphonophores & 3.8 & 0.8 \\
Doliolids & 2.2 & $-{ }^{\mathrm{b}}$ \\
Salps & 2.0 & 2.0 \\
Pteropods & 0.7 & 2.3 \\
Heteropods & 30.9 & $-\mathrm{b}$ \\
Polychaetes & 1.8 & 0.7 \\
Barnacle Cyprids & $-\mathrm{b}$ & $-\mathrm{b}$
\end{tabular}

a either did not occur in 0-150 m layer in day (i.e., $\mathrm{N}: \mathrm{D}$ undefined) or at night (i.e., $\mathrm{N}: \mathrm{D}=$ $0),{ }^{b}$ did not occur 
Figure 1. Sea level anomaly satellite imagery of 2004 Sargasso Sea eddy field prior to initial sampling (A), and fluorescence at $100 \mathrm{~m}$ depth of target eddy feature C1 (B). Several other eddy features (A1, A2, A3, C2) are noted in (A), stars in (B) represent approximate locations of MOCNESS tows (after McGillicuddy et al. 2007). Red square indicates location of Bermuda Atlantic Time-series Study (BATS) site. Satellite ground tracks (A) are shown for Jason (magenta) and ERS/ENVISAT (light blue). 
Figure $1 \mathrm{~A}$ and $\mathrm{B}$.
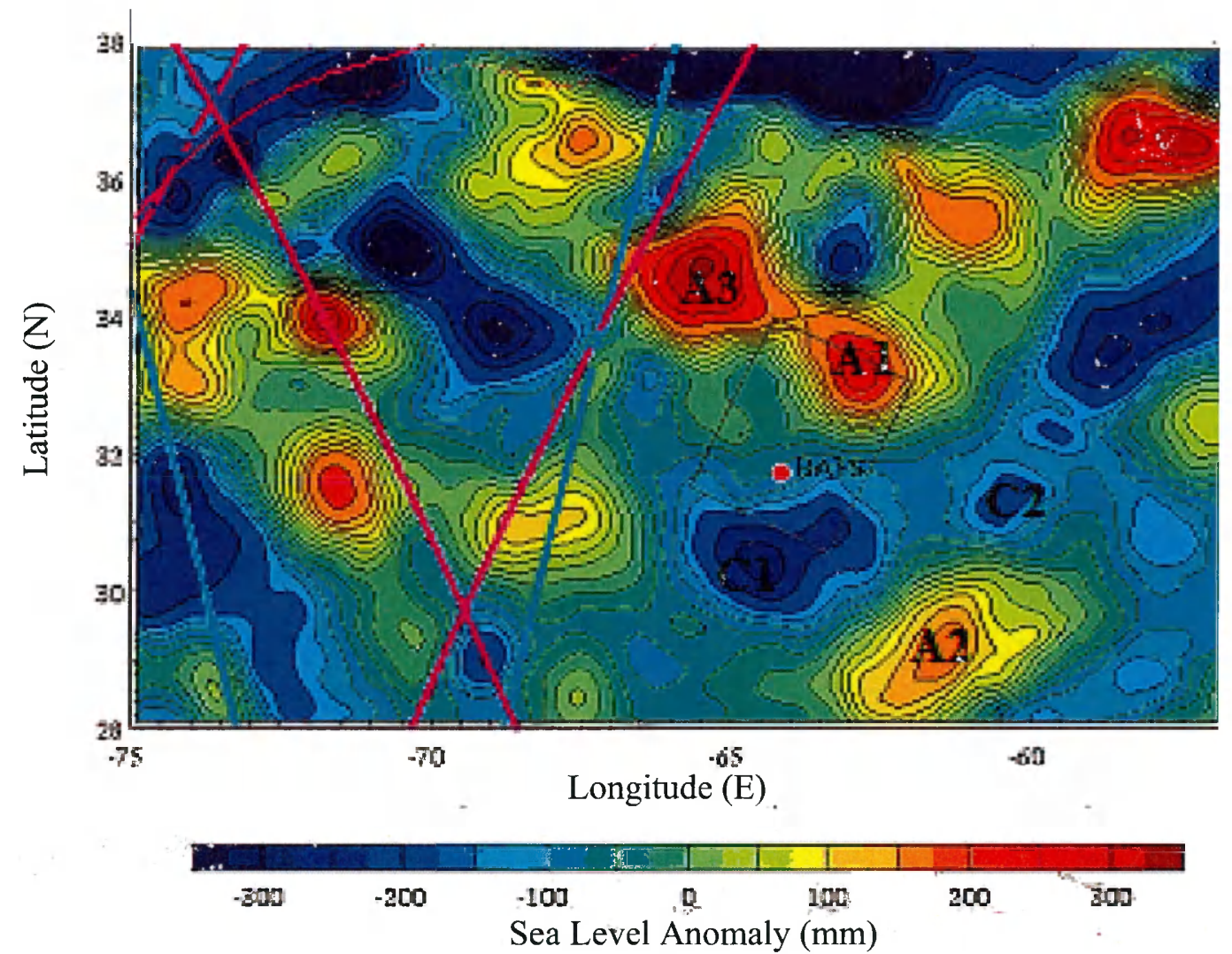

(B)

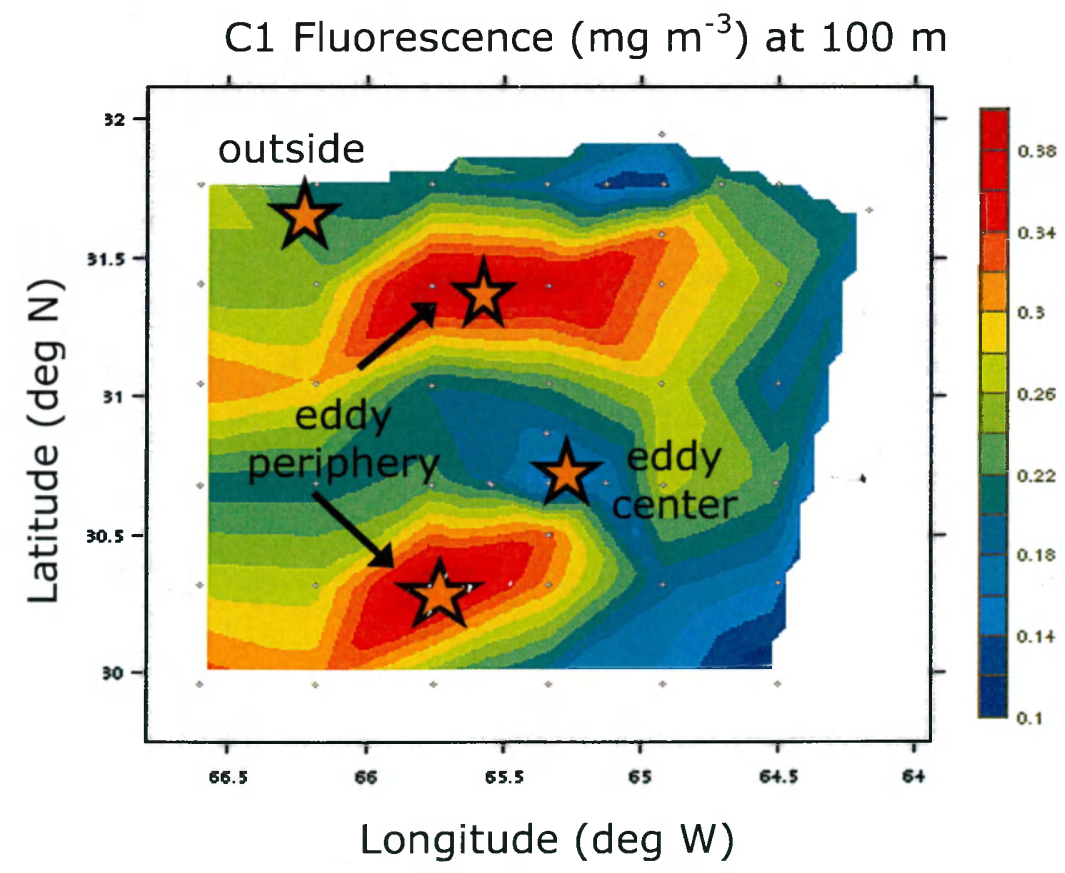


Figure 2. Sea level anomaly satellite imagery of 2005 Sargasso Sea eddy field prior to initial sampling (A), and fluorescence at $90 \mathrm{~m}$ depth of target eddy feature A4 (B). Several other eddy features (A5, C3, C4, C5) are noted in (A), stars in (B) represent approximate locations of MOCNESS tows (after McGillicuddy et al. 2007). Red square indicates location of Bermuda Atlantic Time-series Study (BATS) site. Satellite ground tracks (A) are shown for Jason (magenta) and Geosat Follow-on (GFO) (black). 
Figure $2 \mathrm{~A}$ and $\mathrm{B}$.
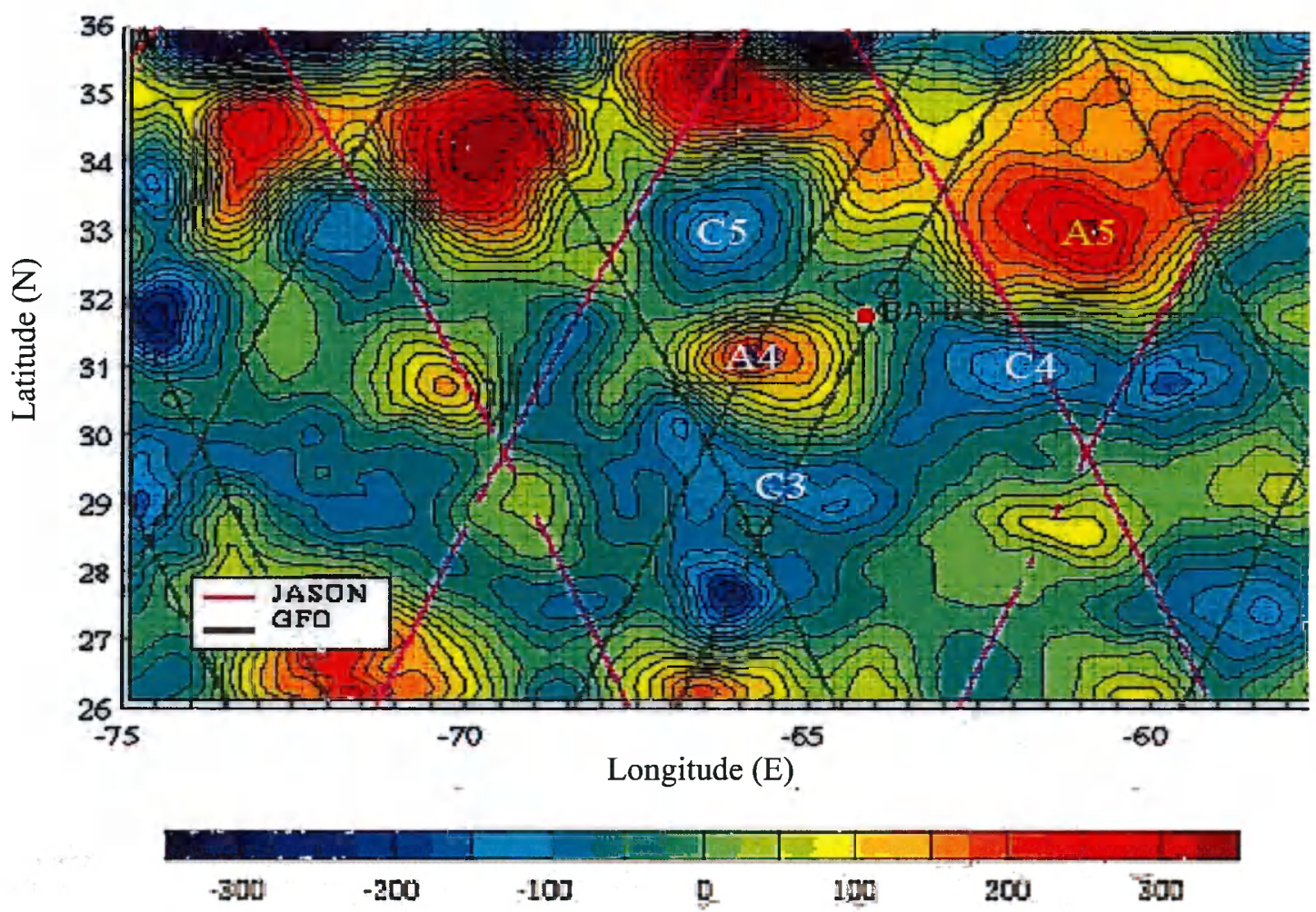

(B)

Sea Level Anomaly (mm)

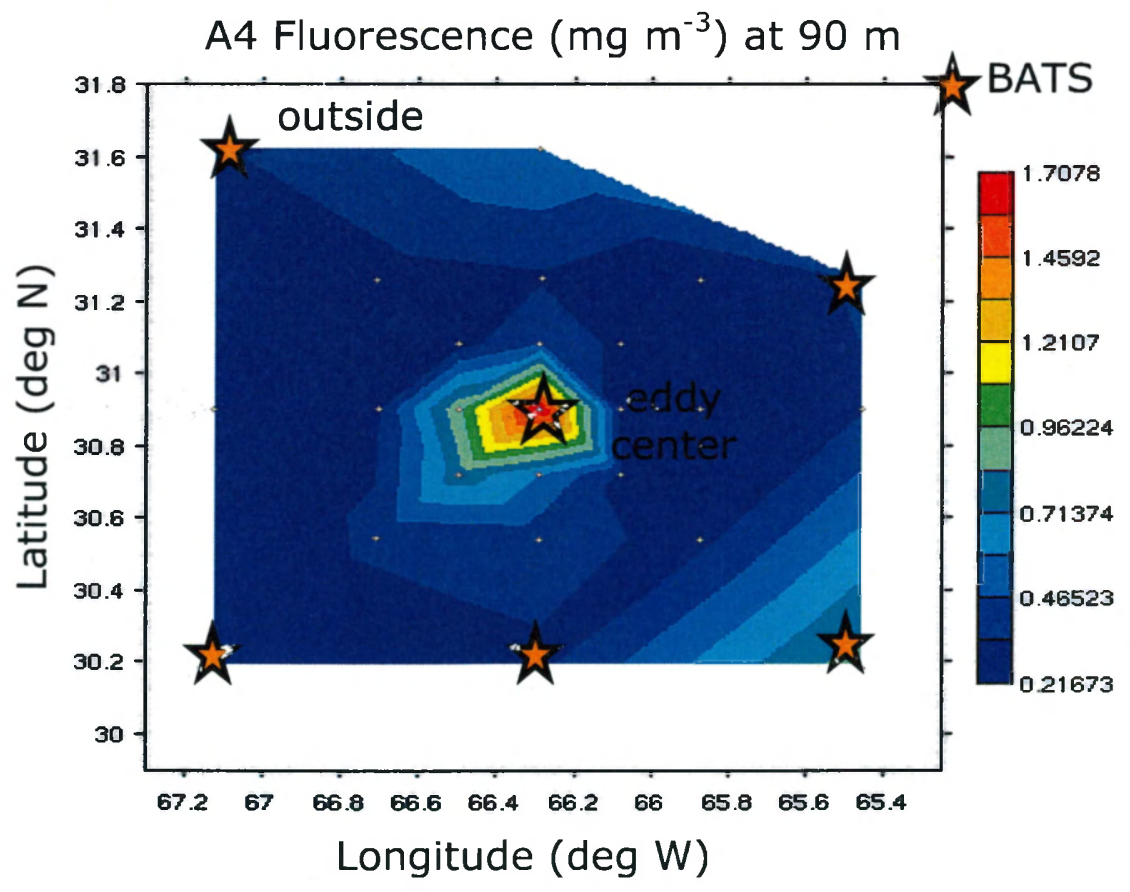


Figure 3. Comparison of epipelagic zone $(0-150 \mathrm{~m})$ integrated abundance of copepopds between cyclone C1, mode-water eddy A4, and 2004/2005 BATS summer means, for daytime and nighttime tows at eddy center, periphery, outside the eddy, and at BATS. Gray bars represent cyclone C1, except at BATS where they represent the 2004 summer mean. White bars represent mode-water eddy A4, except at BATS where they represent the 2005 summer mean. Values are mean $( \pm 1$ s.d.) of integrated abundance $(C 1, n=2$, except for outside station $n=1$; A4, center and outside day $n=4$, center and outside night $n=5$; BATS 2004/2005, $n=6$ ). Periphery stations were not sampled in eddy A4 (see text for explanation). ${ }^{*}$ Represents significant $(\mathrm{p}<0.05$ ANOVA) difference from BATS abundance. 
Figure 3.
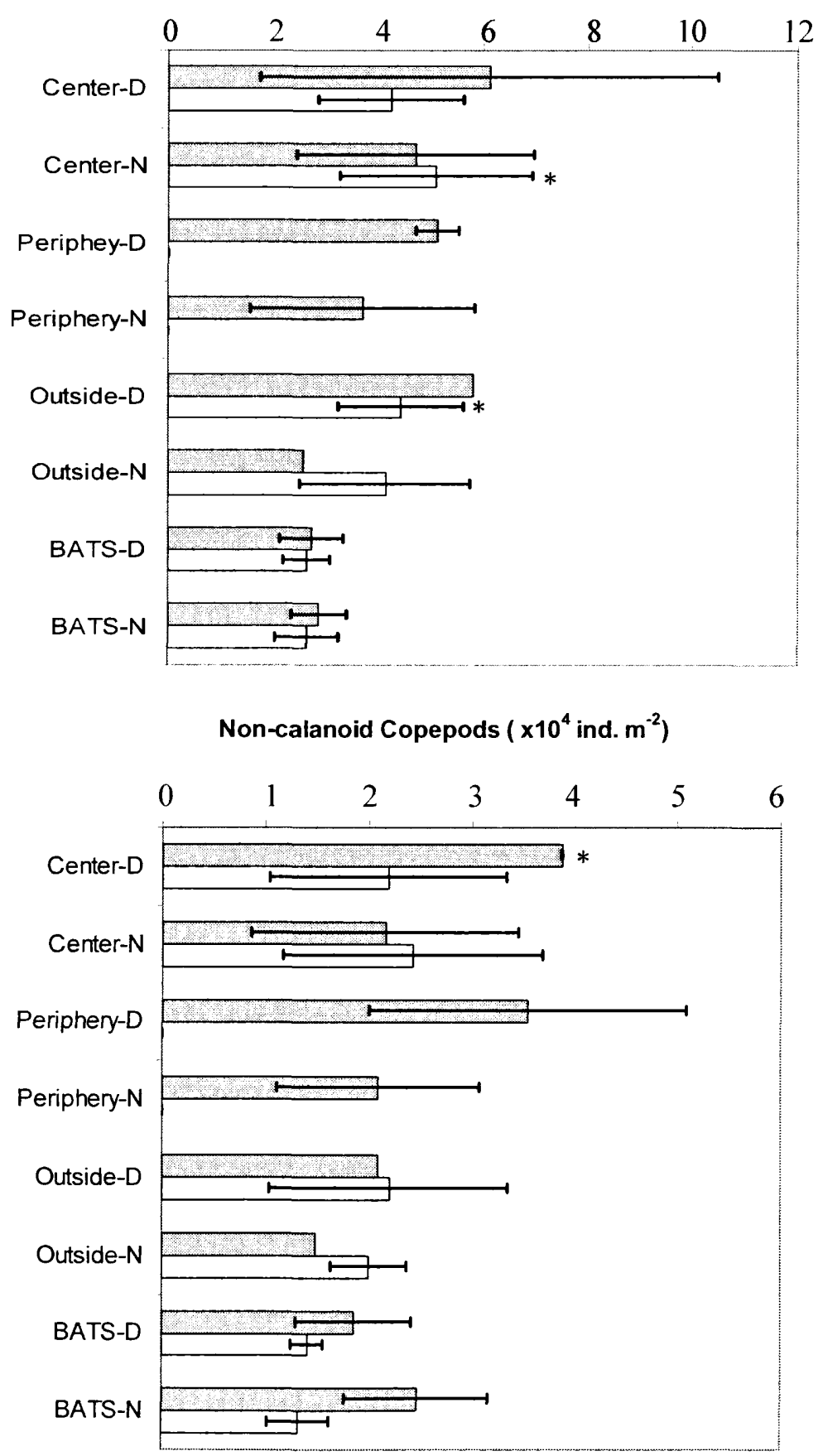

Cyclone C1 / $\square$ Mode-water Eddy A4 /

BATS $2004 \quad$ BATS 2005 
Figure 4. Comparison of epipelagic zone (0-150 m) integrated abundance of crustaceans other than copepods between cyclone C1, mode-water eddy A4, and BATS, for daytime and nighttime tows at eddy center, periphery, outside the eddy, and at BATS. Figure as described in Fig. 3. 
Figure 4.
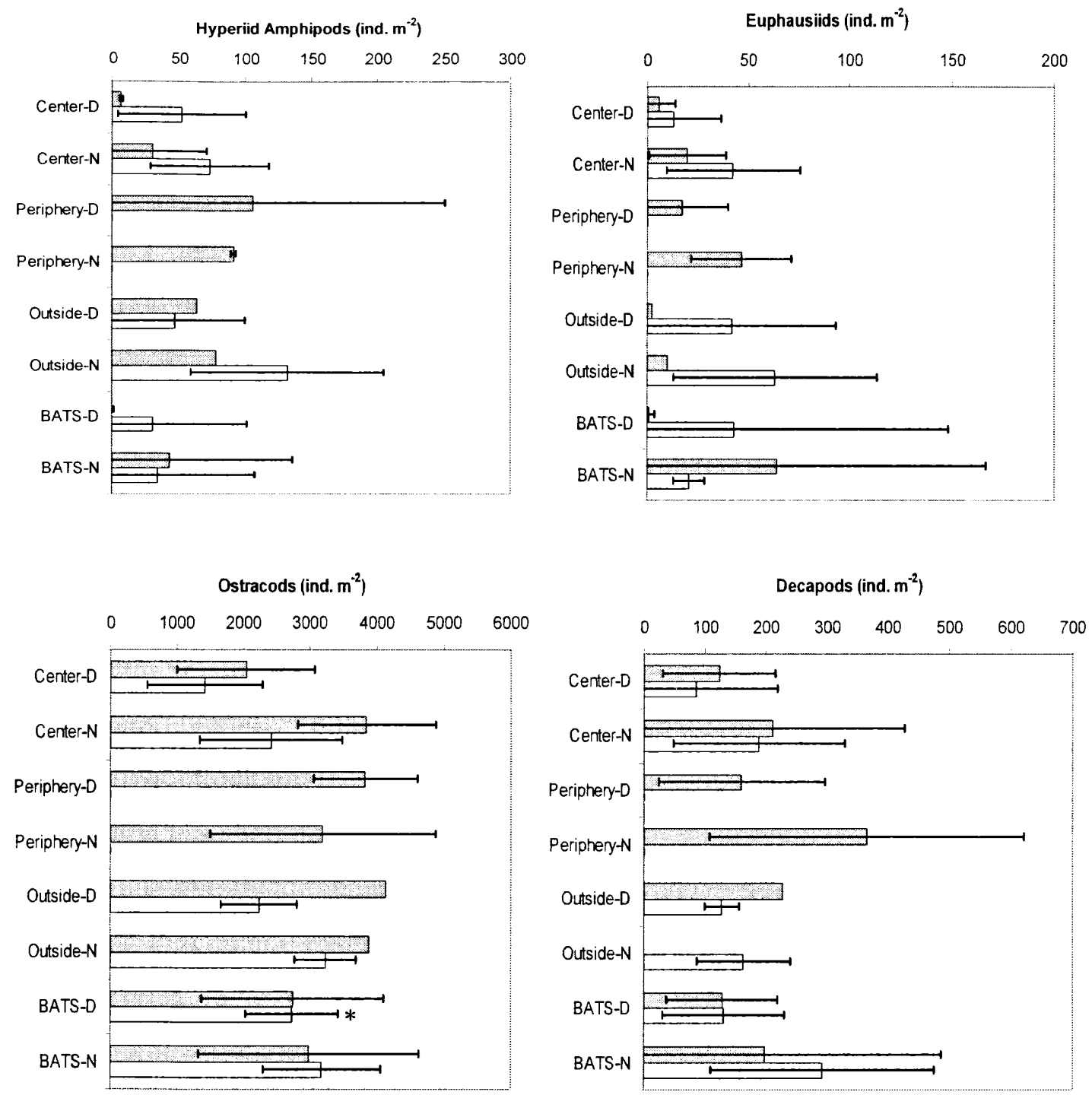

Cyclone $\mathrm{C} 1 /$

BATS 2004

Mode-water Eddy A4 /

BATS 2005 
Figure 5. Comparison of epipelagic zone $(0-150 \mathrm{~m})$ integrated abundance of gelatinous zooplankton between cyclone C1, mode-water eddy A4, and BATS, for daytime and nighttime tows at eddy center, periphery, outside the eddy, and at BATS. Figure as described in Fig. 3. 
Figure 5. Chaetognaths (ind. $\mathrm{m}^{-2}$ )

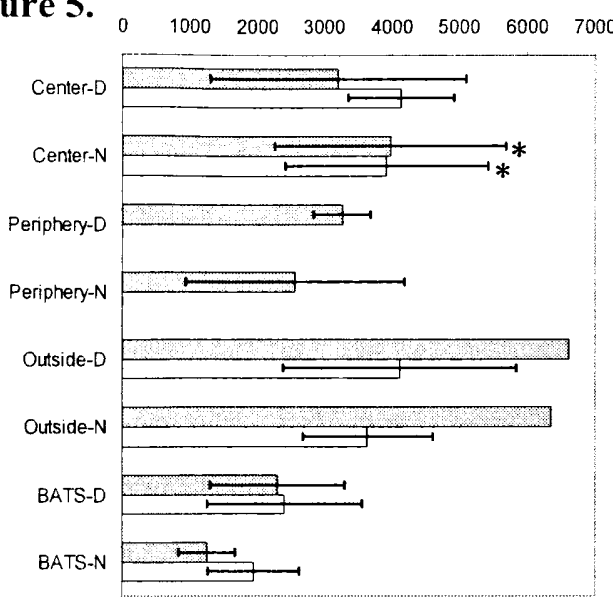

Doliolids (ind. $\mathrm{m}^{-2}$ )

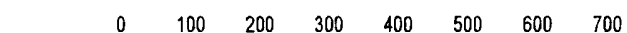

$$
\text { Center- }
$$

$\begin{array}{llllllll}0 & 100 & 200 & 300 & 400 & 500 & 600 & 700\end{array}$

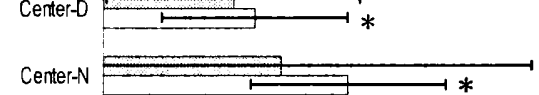

Periphery-D $\square$

Periphery-N $\rightleftharpoons$

Outside-D

Outside-N

BATS-D

BATS-N $\rightleftharpoons$

Pteropods (ind. $\mathrm{m}^{-2}$ )

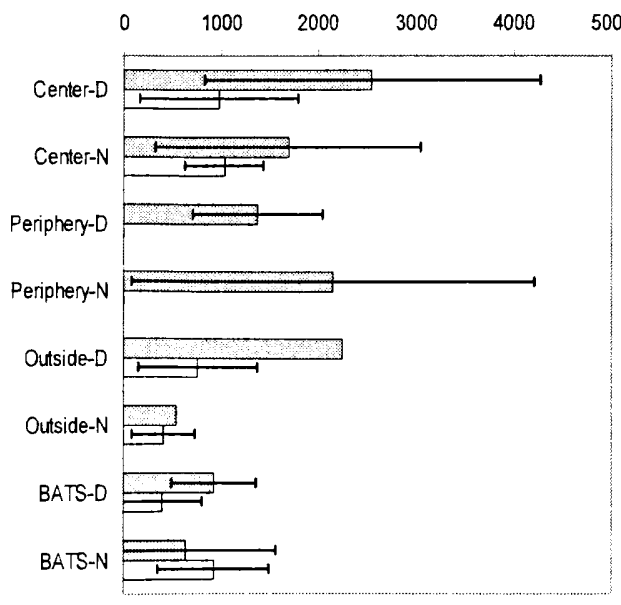

Cyclone $\mathrm{C} 1 /$

BATS 2004

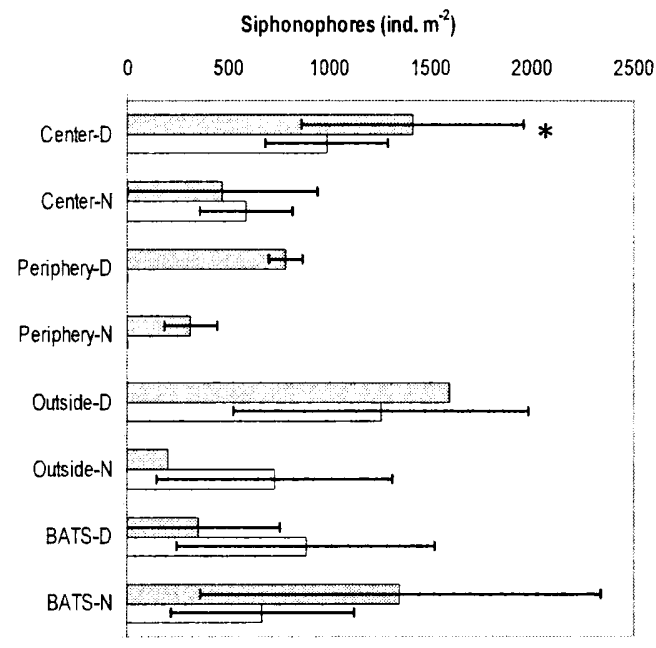

Heteropods (ind. $\mathrm{m}^{-2}$ )
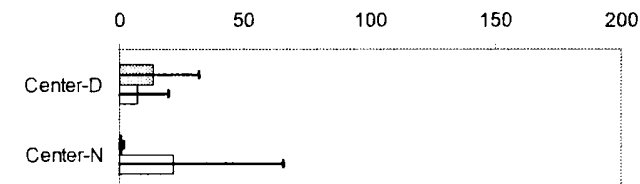

Periphery-D

Periphery-D

Peniphery-N

Outside-D

Outside-N

BATS-D

BATS-N

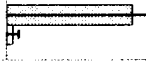

Polychaetes (ind. $\mathrm{m}^{-2}$ )

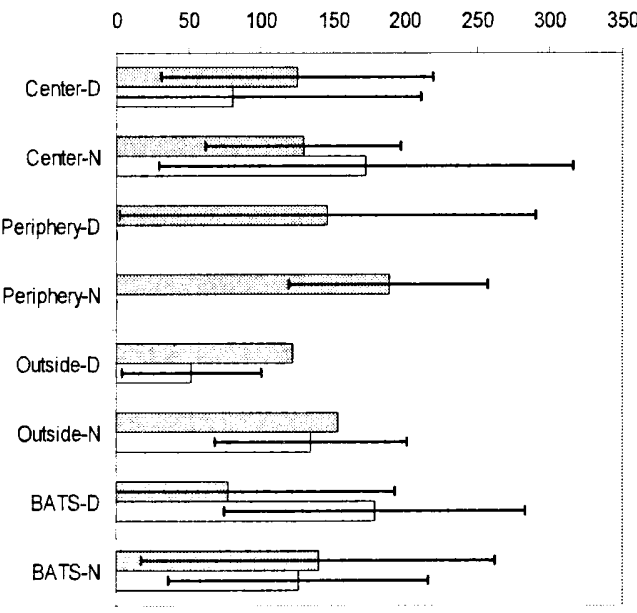

$\square$ Mode-water Eddy A4 /

BATS 2005 
Figure 6. Percent abundance of epipelagic non-copepod zooplankton in cyclone $\mathrm{C} 1$ and mode-water eddy A4. Abundance is mean of day and night tows for each depth interval. Periphery stations were not sampled in eddy A4 (see text for explanation). 
Figure 6.

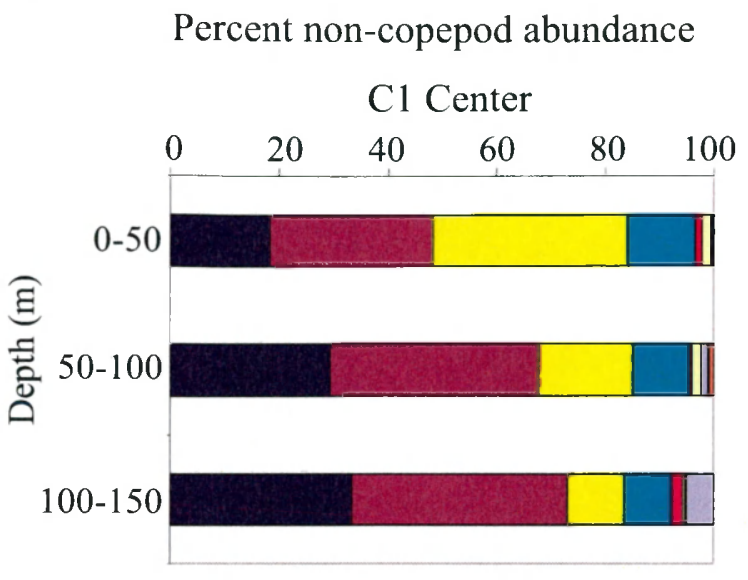

Percent non-copepod abundance
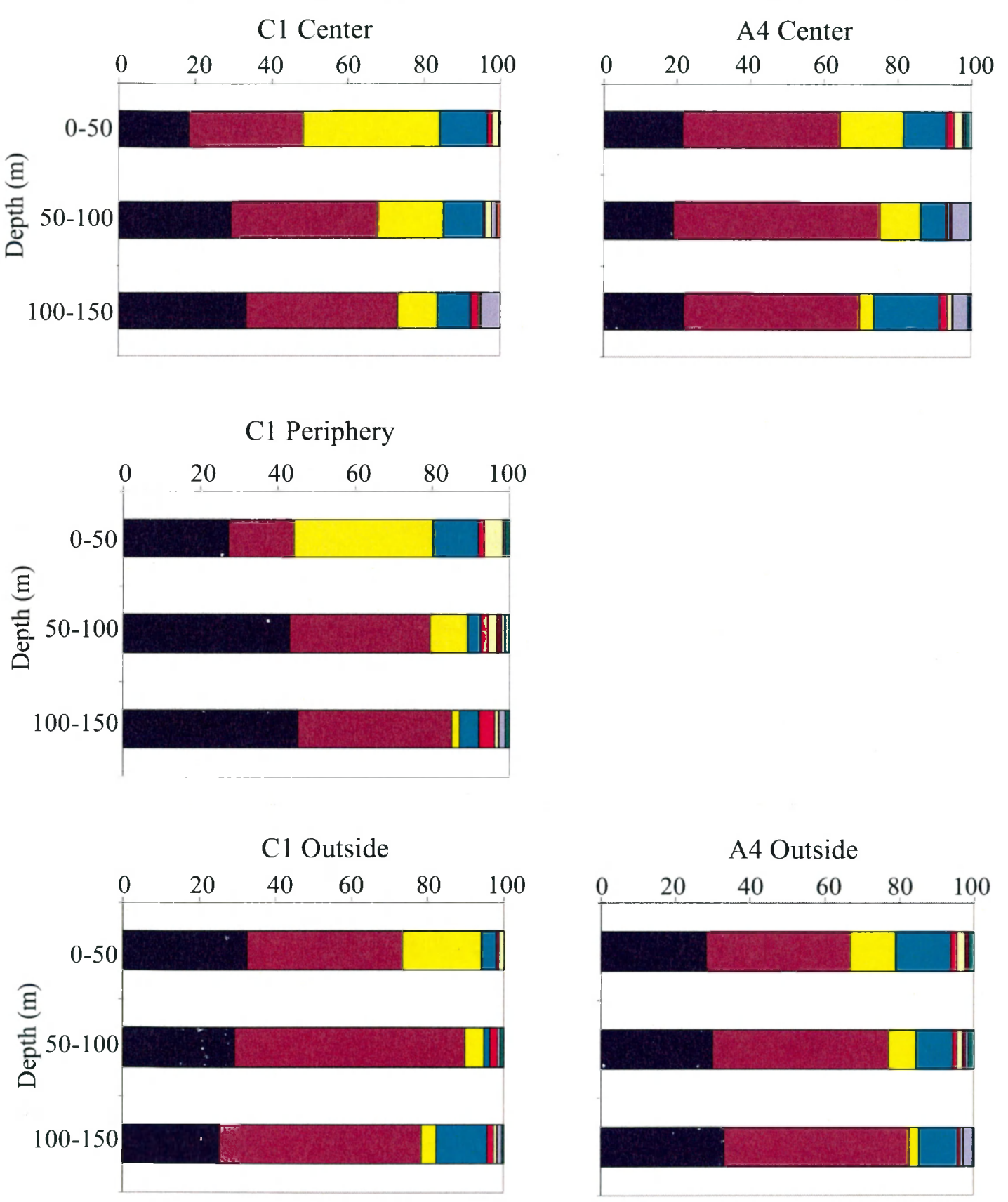

Ostracods $\quad$ Chaetognaths Pteropods Siphonophores $\square$ Polychaetes $\square$ Decapods $\square$ Euphausiids $\square$ Doliolids Hyperiid Amphipods $\square$ Gammarid Amphipods $\square$ Heteropods 
Figure 7. Day/night profiles of copepod taxonomic abundance at the center and outside of mode-water eddy A4. Values are mean ( \pm 1 s.d.) of $n=4$ for center/outside day and $\mathrm{n}=5$ for center/outside night. Note abundance scales differ by taxonomic group, and depths are $50 \mathrm{~m}$ intervals in the top $200 \mathrm{~m}$, and $100 \mathrm{~m}$ thereafter. 
Figure 7.
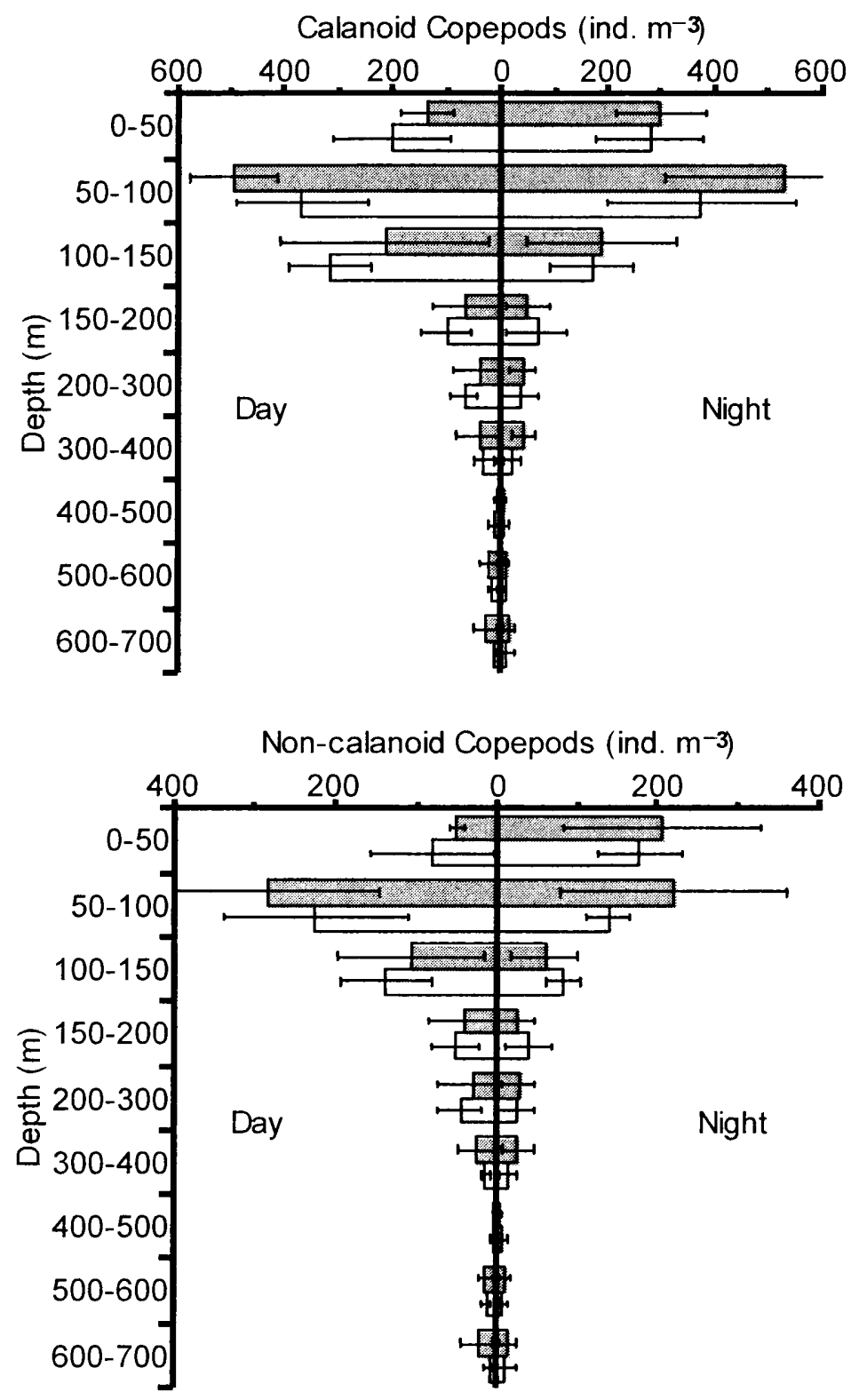

$\square$ Eddy Center $\square$ Outside Eddy 
Figure 8. Percent abundance of non-copepod zooplankton during day and night inside and outside mode-water eddy A4. Values are the mean of $n=4$ (center/outside, day), or $\mathrm{n}=5$ (center/outside night). 
Figure 8.

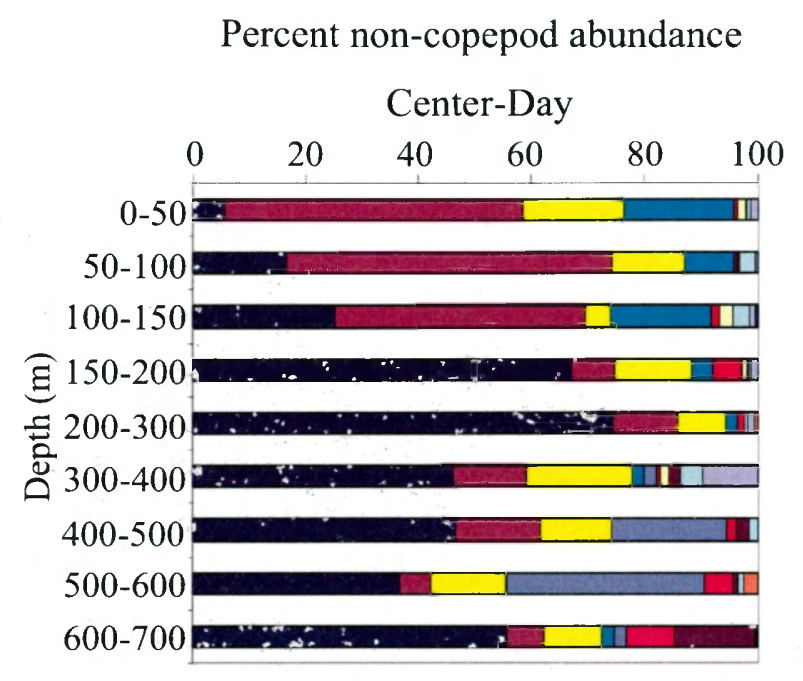

Percent non-copepod abundance
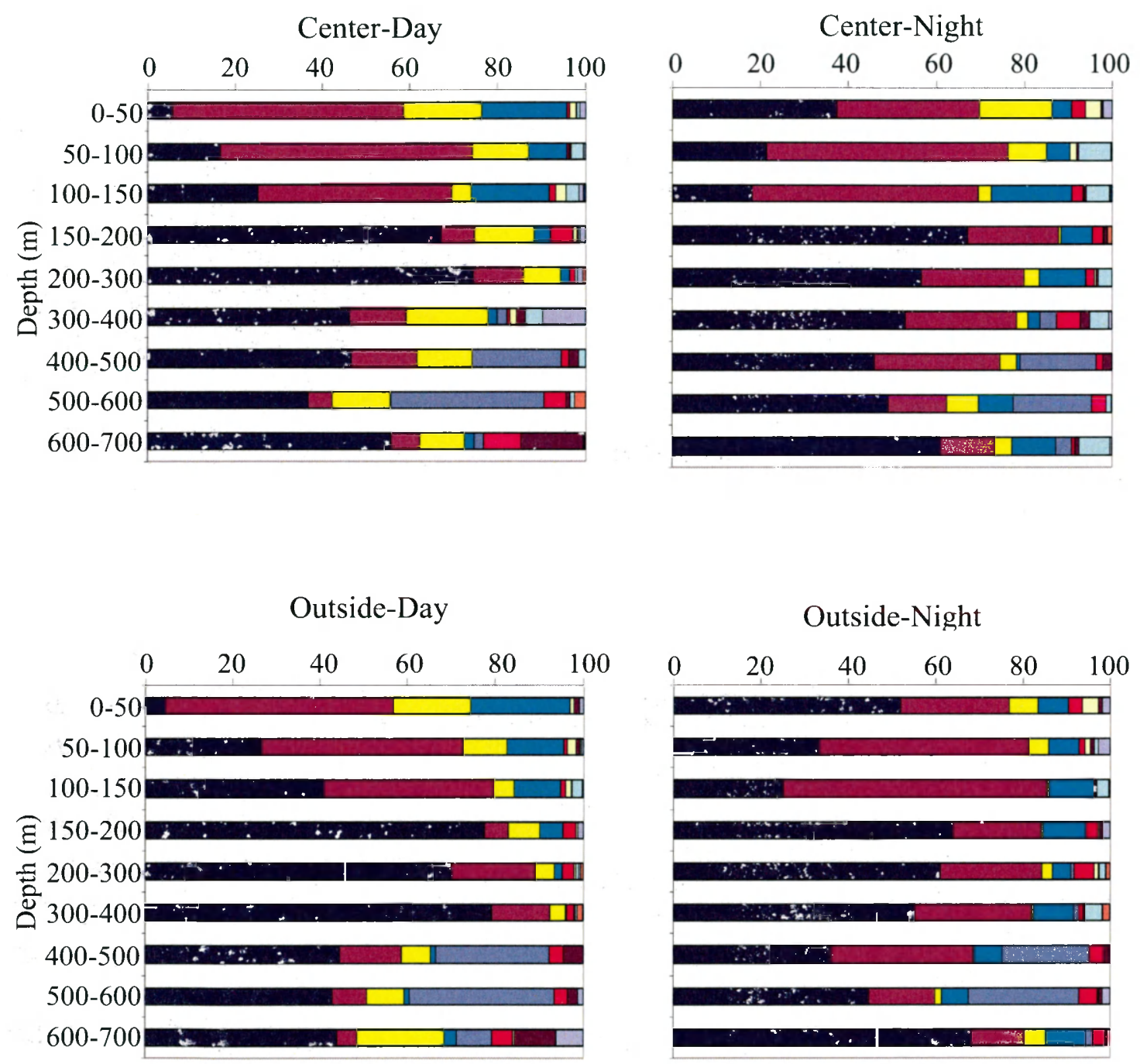

- Ostracods $\square$ Chaetognaths $\square$ Pteropods $\square$ Siphonophores

$\square$ Barnacle Cyprids $\square$ Polychaetes $\square$ Decapods $\square$ Euphausiids

$\square$ Doliolids $\square$ Hyperiid Amphipods $\square$ Gammarid Amphipods

$\square$ Heteropods 
Figure 9. Day/night profiles of other crustacean taxonomic abundance in the center and outside of mode-water eddy A4. Figure as described in Fig. 7. 
Figure 9.
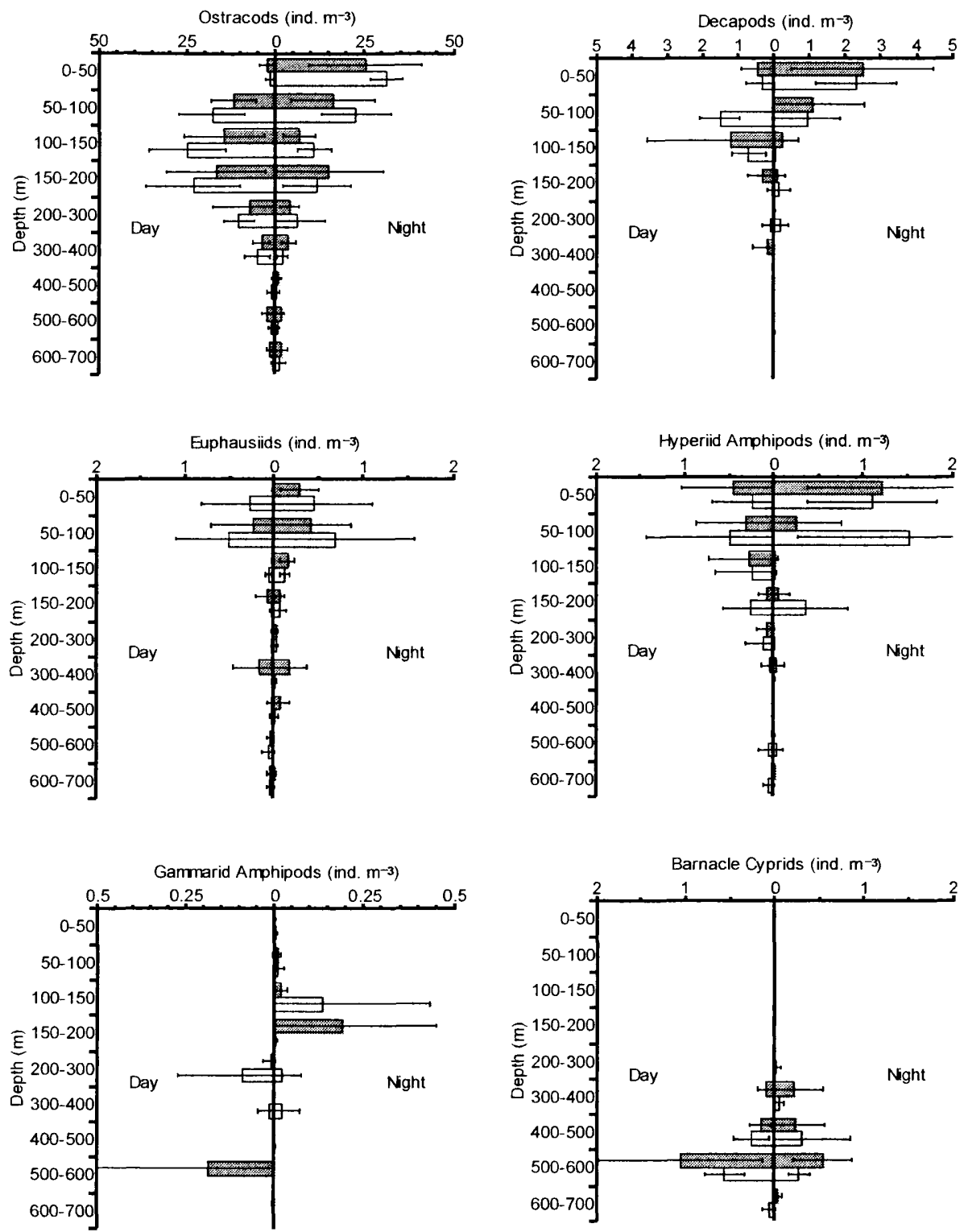

$\square$ Eddy Center $\square$ Outside Eddy 
Figure 10. Day/night profiles of gelatinous zooplankton taxonomic abundance in the center and outside of mode-water eddy A4. Figure as described in Fig. 7. 
Figure 10.
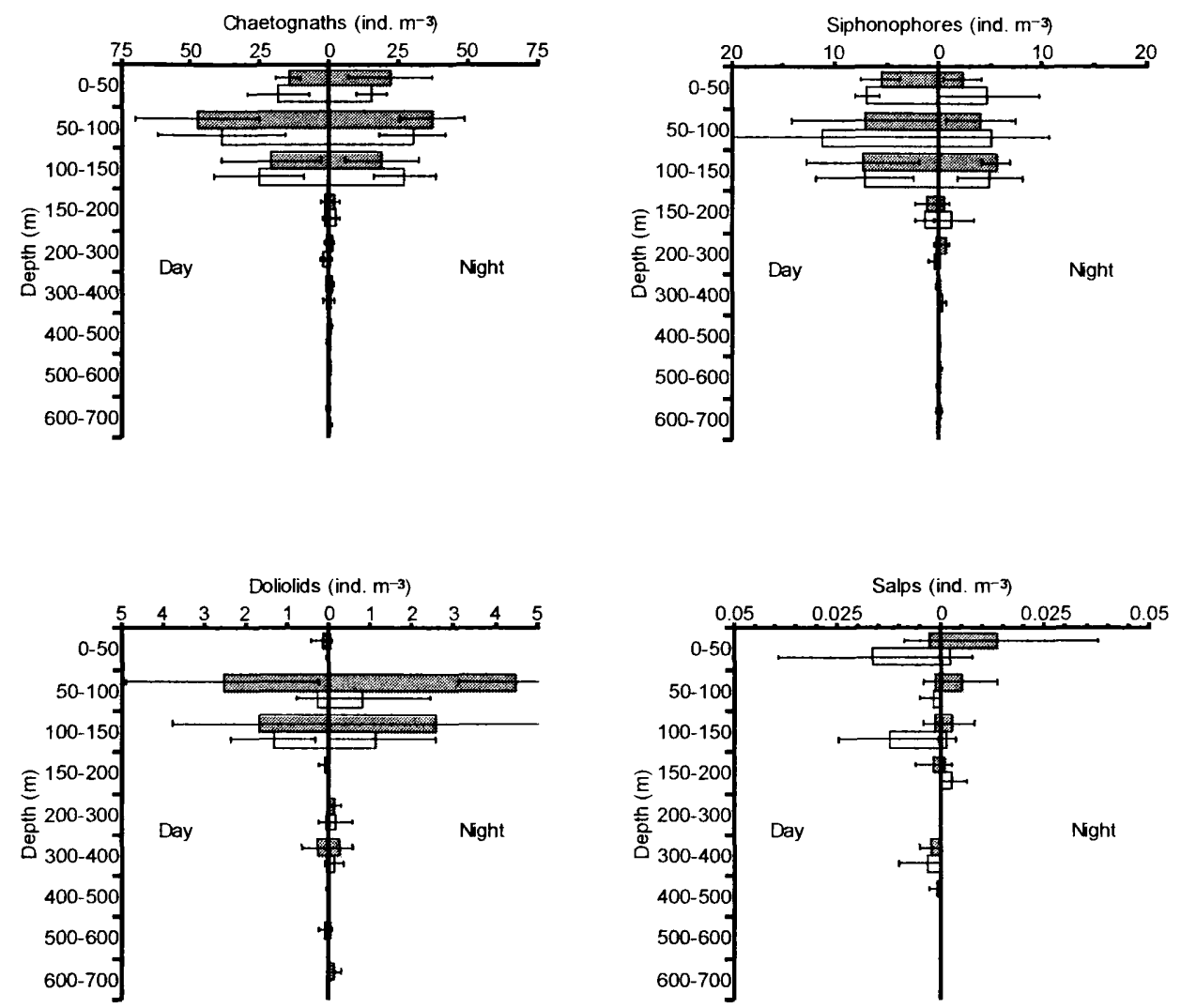

$\square$ Eddy Center $\square$ Outside Eddy 
Figure 11. Day/night profiles of gelatinous zooplankton taxonomic abundance in the center and outside of mode-water eddy A4. Figure as described in Fig. 7. 
Figure 11.
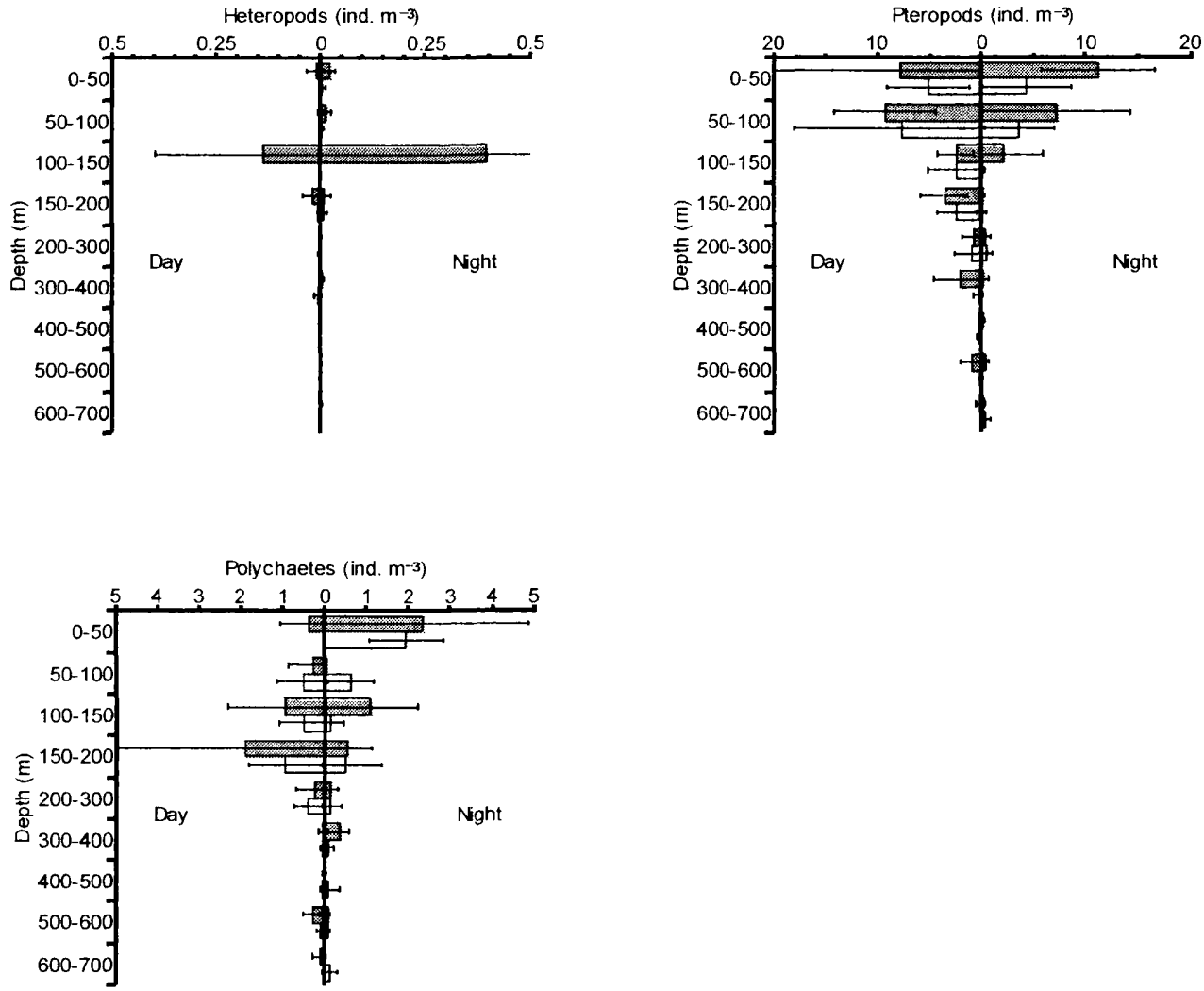

$\square$ Eddy Center $\square$ Outside Eddy 
Figure 12. Changes in epipelagic abundance of total copepods (calanoid + noncalanoid), chaetognaths, and ostracods over time during day and night in cyclone $\mathrm{C} 1$ center* and periphery, day 1 (22 June 2004) to day 43 (4 August 2004). No outside eddy comparison is shown as only one outside eddy station was sampled (i.e., no time lapse). *Excludes eddy center night due to short ( 3 day) interval between tows. Each point represents $n=1$ (tow). 
Figure 12.

Total Copepods

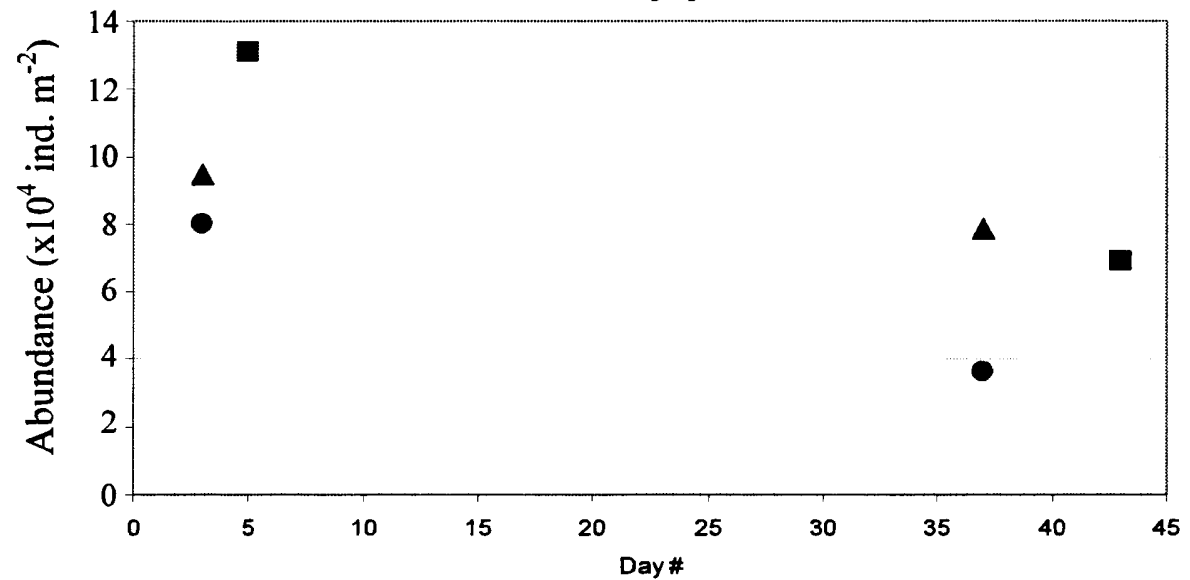

Chaetognaths

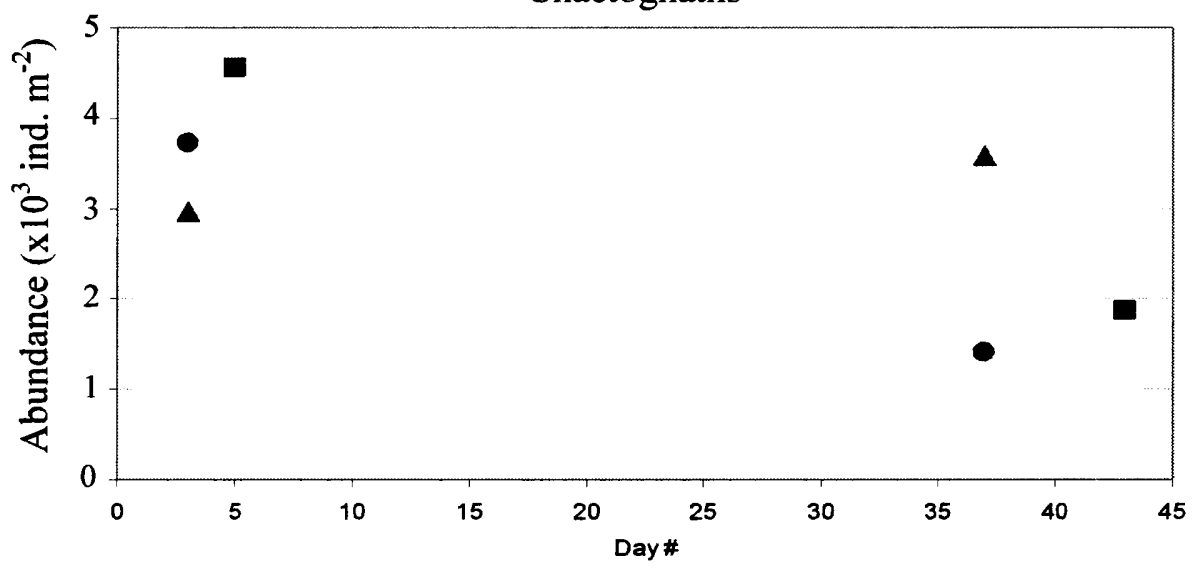

Ostracods

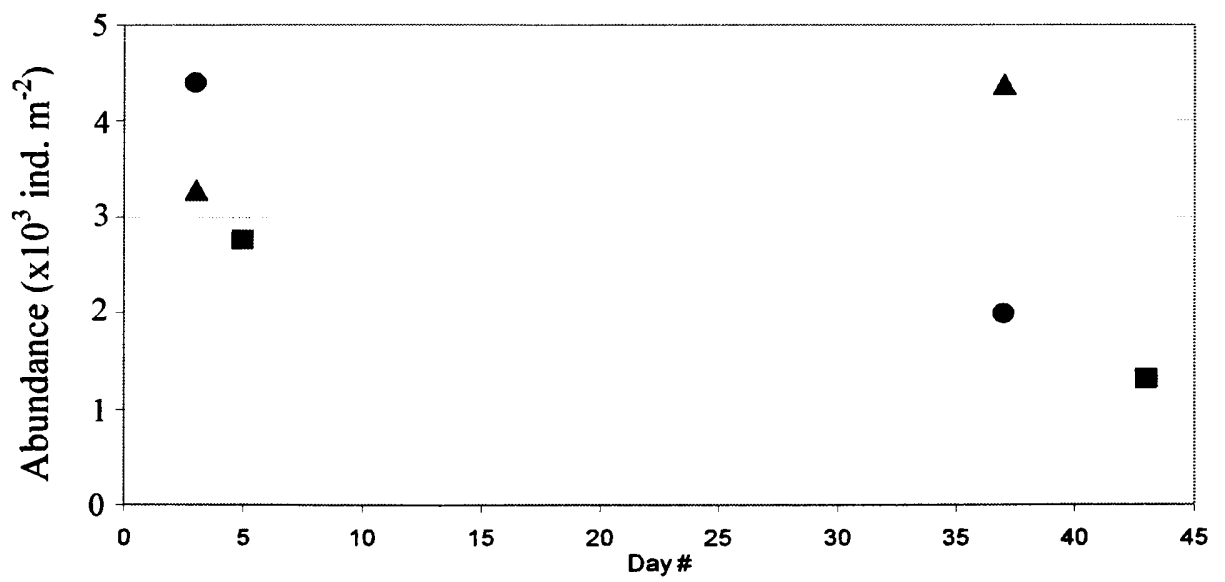

- Center-D $\Delta$ Periphery-D $\bigcirc$ Periphery-N 
Figure 13. Changes in epipelagic abundance of total copepods (calanoid + noncalanoid), chaetognaths, and ostracods over time during day and night tows at modewater eddy A4 center and outside, day 1 (25 June 2005) to day 62 (25 August 2005). Each point represents $n=1$ (tow). 
Figure 13.

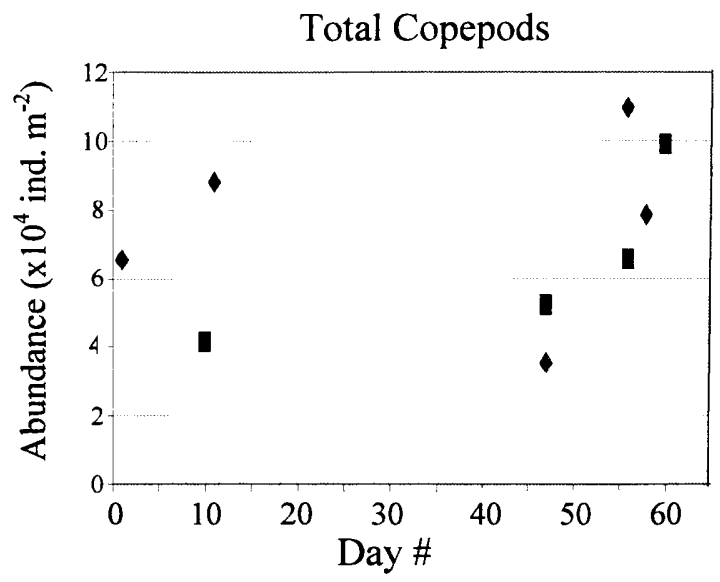

Total Copepods
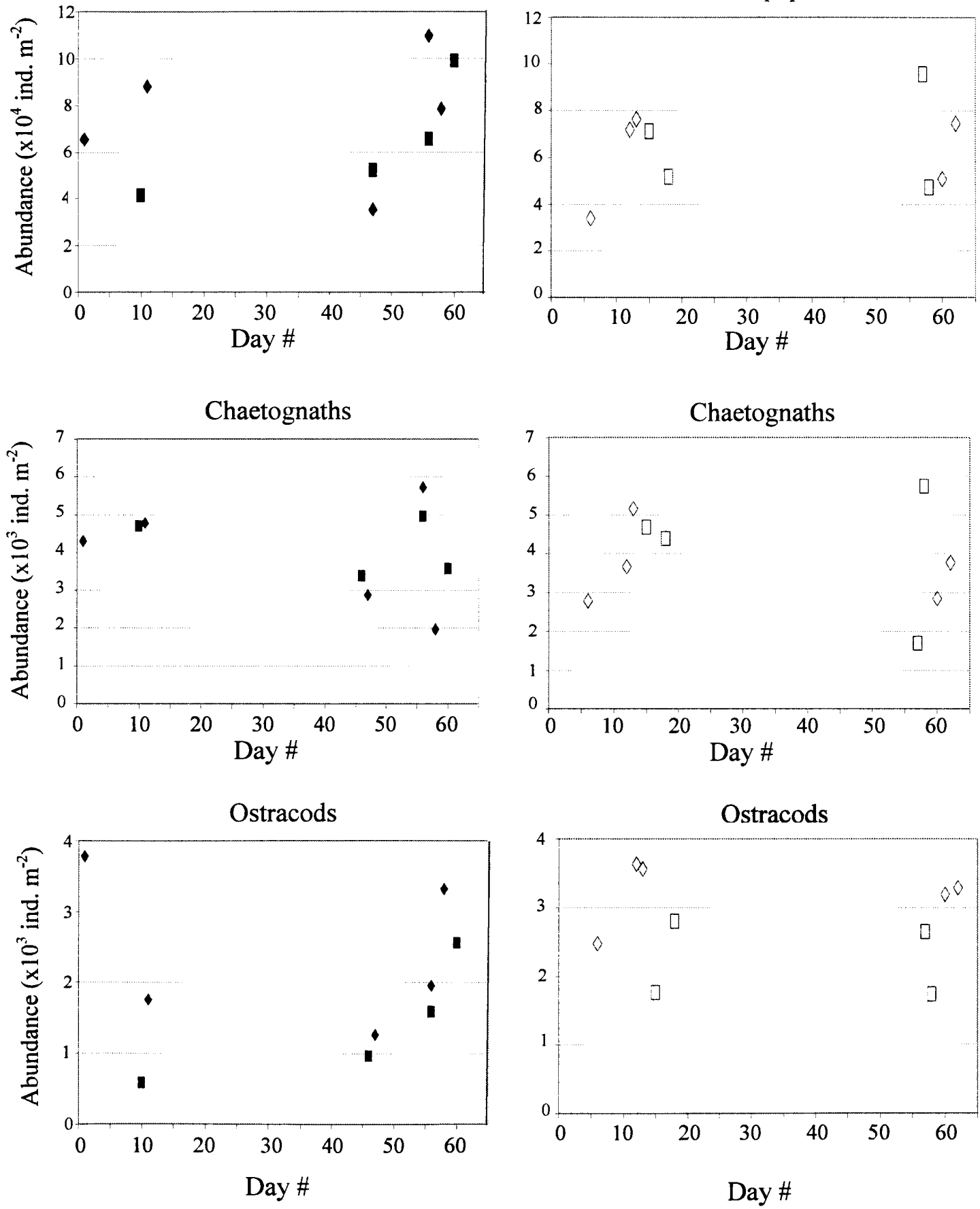

$\square$ Center-D $\square$ Outside-D

$\diamond$ Center-N $\diamond$ Outside-N 


\section{VITA}

\section{Bethany Rose Eden}

Born in East Stroudsburg, Pennsylvania on July 19, 1983. Graduated from East Stroudsburg High School-South in 2001. Received a B.S. in Marine Science and Environmental Geology from Rider University in 2005. Completed a summer internship in blue crab aquaculture at the University of Maryland Biotechnology Institute's Center of Marine Biotechnology in Baltimore Maryland. Entered the M.S. program at the Virginia Institute of Marine Science, College of William and Mary in 2005 under graduate advisor Dr. Deborah K. Steinberg. 